CAHIERS DE

NARRATOLOGIE
Cahiers de Narratologie

Analyse et théorie narratives

12 | 2005

Récit et éthique

\title{
Quelques enjeux de l'exemplarité dans le Calila e Dimna et le Sendebar
}

\section{Olivier Biaggini}

\section{(2) OpenEdition}

1 Journals

Édition électronique

URL : https://journals.openedition.org/narratologie/28

DOI : 10.4000/narratologie.28

ISSN : 1765-307X

Éditeur

LIRCES

\section{Référence électronique}

Olivier Biaggini, «Quelques enjeux de l'exemplarité dans le Calila e Dimna et le Sendebar », Cahiers de Narratologie [En ligne], 12 | 2005, mis en ligne le 20 avril 2005, consulté le 21 septembre 2021. URL : http://journals.openedition.org/narratologie/28 ; DOI : https://doi.org/10.4000/narratologie.28

Ce document a été généré automatiquement le 21 septembre 2021.

\section{(c) (i) (2) $\Theta$}

Cahiers de Narratologie - Analyse et théorie narratives est mis à disposition selon les termes de la licence Creative Commons Attribution - Pas d'Utilisation Commerciale - Pas de Modification 4.0 International. 


\title{
Quelques enjeux de l'exemplarité dans le Calila e Dimna et le Sendebar
}

\author{
Olivier Biaggini
}

1 Le Calila e Dimna et le Sendebar sont deux recueils de contes ou exempla d'origine orientale, traduits en castillan au milieu du XIIIe siècle sous l'autorité de grands personnages de la cour de Castille (respectivement l'infant Alphonse, futur Alphonse $\mathrm{X}$, et son frère Fadrique) ${ }^{1}$. Originaires de l'Inde, mais ayant transité par la Perse et le monde arabomusulman, ces recueils de récits exemplaires ont pu être reçus en Occident sans qu'aucun effort particulier de christianisation soit nécessaire: les préceptes moraux qu'ils véhiculent sont suffisamment universels pour être acceptés tels quels, ou presque, par toutes les civilisations qui ont accueilli ces textes. Du point de vue strictement éthique, ces recueils ne présentent donc aucune véritable nouveauté pour le monde chrétien qui les reçoit. D'ailleurs, en lisant les contes, les similitudines et les sentences qui s'y trouvent, on chercherait en vain à reconstruire la doctrine morale qui aurait orienté leur composition. Tous les contes de ces recueils sont encadrés par un appareil argumentatif parfois très rigide qui leur assigne une portée éthique explicite (le plus souvent sous la forme d'une sentence ou «moralité ») mais, considérées dans leur ensemble, ces préceptes ne forment que très vaguement un système philosophique et n'interfèrent presque jamais de façon dialectique. D'ailleurs, les normes pratiques que l'on déduit des contes sont souvent contradictoires. Mieux : parfois, des situations narratives parallèles, pour ne pas dire similaires, conduisent à des moralités opposées. Plutôt qu'une doctrine cohérente et fermée, les recueils prétendent donc transmettre un modèle ouvert de comportement: les exemples convoqués, on le sent bien, sont irréductibles à une généralisation éthique définitive - puisqu'un contre-exemple peut toujours venir la nuancer ou la contredire. C'est en ce sens que l'on a pu parler, pour le Calila e Dimna en particulier, de "morale introuvable $»^{2}$ et l'on verra que l'on peut aussi entendre cette expression en un sens bien plus radical. Je ne cherche pas à nier l'exemplarité des récits, bien au contraire, mais plutôt à poser d'emblée la question de la place de la morale dans cette exemplarité. 
Qu'est-ce qui, dans un récit exemplaire, peut s'ériger en norme de comportement ? Est-ce la moralité qui couronne le récit et qui est censée en résumer la portée ?; est-ce le récit lui-même, par ses structures internes?; ou est-ce enfin leur rapport même, la tension toujours ouverte que le texte déploie entre le récit et sa morale explicite ? L'encadrement du récit par la morale, souvent très rigide, ne constitue que la couche la plus superficielle de l'exemplarité : il convient de dépasser la vision d'un récit comme « matière première vierge » qui se coulerait ensuite dans un moule éthique ou, a contrario (mais cela revient peut-être au même) celle du récit purement illustratif, entièrement construit à partir de la moralité qu'il est censé prouver. Les structures narratives elles-mêmes contribuent à renforcer, enrichir et orienter cette exemplarité qui, à la surface du texte, leur semblait extérieure (antérieure ou surajoutée). Mais si l'exemplarité se forge en grande partie par le récit et par des moyens de récit, qu'est-ce qui distingue l'exemplum d'un autre type de récit? Par ailleurs, aucun contenu éthique univoque ne saurait dériver de la narration elle-même: il suffirait de citer le cas d'un conte du Sendebar («Senescalcus») qui, à différentes étapes de sa transmission, en est venu à produire deux moralités opposées ${ }^{3}$. Reste la solution bien commode qui consiste à concevoir l'exemplarité comme tension entre le récit et sa morale explicite, mais a-t-on vraiment avancé ? N'est-ce pas là un moyen terme qui élude le problème au lieu de le résoudre? Je n'ai évidemment pas les moyens de répondre à ces questions : mon but est seulement de mieux les poser à partir d'une approche des deux recueils.

Dans le cas précis du Calila e Dimna et du Sendebar, la réflexion ne pourra prendre en compte deux éléments seulement (le récit et sa moralité), mais devra tenir compte d'un troisième terme, directement induit par les structures narratives des recueils. Si ces recueils n'ont rien apporté de décisif à l'Occident dans le champ strictement doctrinal, ils ont apporté en revanche un modèle narratif nouveau fondé sur l'enchâssement des récits. Ce n'est pas technique de l'enchâssement (le récit dans le récit) qui, en elle-même, constitue une nouveauté, mais sa systématisation, et parfois son redoublement, qui en font le fondement de la structure narrative des recueils. Dans la littérature castillane médiévale, ce modèle structurel du récit sera réutilisé par des auteurs postérieurs tels l'Archiprêtre de Hita dans son Libro de buen amor ou Don Juan Manuel dans El conde Lucanor. Le modèle narratif d'origine orientale n'est donc pas resté cantonné aux traductions mais a largement été assimilé par la littérature occidentale. Un cas plus célèbre, le Décameron de Boccace, montre à quel point l'introduction de ces schémas narratifs pouvait renouveler la structure des recueils de contes. À ce propos, il convient de décrire très brièvement cette structure d'ensemble et, pour commencer, de préciser ce terme équivoque de "recueil» (ou " collection»). Par ce terme, on ne saurait entendre un de ces catalogues de récits tels qu'il en existe au Moyen Âge, notamment à l'intention des prédicateurs, et qui, formellement, se réduisent à une juxtaposition d'exempla. La structure narrative essentielle du Calila et du Sendebar est la suivante : un récit principal (appelé aussi trame principale ou, en termes plus techniques, récit-cadre) met en scène des personnages qui, ponctuellement, prennent la parole et relatent des exempla ou des contes, transcrits au style direct dans le corps du texte. Dans le récit de premier niveau (le récit-cadre) sont donc intégrés des récits de deuxième niveau (récits enchâssés) relatés par les personnages du récit-cadre en fonction des contraintes de l'intrigue. De façon très embryonnaire dans le Sendebar, mais beaucoup plus systématiquement dans le Calila, on trouve également quelques narrations de troisième niveau: le conte enchâssé dans le récit-cadre devient à son tour le récit-cadre d'un nouvel enchâssement, selon un procédé 
typique de certaines œuvres orientales, dont Les mille et une nuits. Mon but est d'observer l'impact de cette structure sur l'exemplarité du récit. Affaiblit-elle ou renforce-t-elle la dimension éthique du récit? Ou, pour passer à une approche moins quantitative : en quoi permet-elle la mise en place d'une exemplarité spécifique qui fonctionne moins comme l'interaction entre un récit et une morale que comme l'interaction entre deux récits?

Après avoir brièvement présenté les textes et leurs structures narratives, je tenterai une double étude de cas consacrée à un conte du Sendebar et à un conte du Calila.

I. PrésentationA. Origine, transmission et transformation des œuvres

L'histoire de la transmission du Calila est bien connue dans ses grandes lignes ${ }^{4}$. L'œuvre dérive de récits indiens d'inspiration bouddhique qui mettent en scène des animaux, qui furent composés en sanskrit dans les premiers siècles de notre ère, et dont la diffusion a dû être aussi bien orale qu'écrite. Ces récits ont eux-mêmes été regroupés assez tôt en collections nommées tantras dont le but affiché était de proposer aux princes des règles de conduite et de bon gouvernement. L'une de ces collections qui est parvenue jusqu'à nous, le Panchatantra ou « livre des cinq tantras » (IIIe siècle), a fourni à la tradition du Calila, directement ou indirectement, une bonne part de sa matière narrative. À partir de la version sanskrite primitive, le texte a trouvé sa place dans d'autres cultures grâce à des traductions en diverses langues, comme le syriaque ou le tibétain, et surtout le persan ( pahlevi) qui a permis à son tour la transmission de l'œuvre au monde musulman. En effet, au VIIIe siècle, un perse islamisé de Bagdad, Muhamad Ibn al-Muqaffa', personnage dont nous gardons des traces historiques précises ${ }^{5}$, compose une traduction arabe qui allait être vouée à une diffusion immense dans le monde musulman : le Kalila wa Dimna. On n'a pas conservé la version persane originale mais, au terme du prologue de sa traduction arabe, Ibn al-Muqaffa' en atteste l'existence. Par ailleurs, dans une deuxième pièce liminaire, il attribue cette version à un sage persan, Borzouyeh (qui deviendra Berzebuey dans la version castillane), médecin et philosophe. Ce Borzouyeh, sur l'ordre du roi Chosroes, aurait entrepris un grand voyage en Inde au terme duquel il aurait rapporté des livres, dont l'œuvre qui nous occupe, qu'il aurait traduite du sanskrit au persan. Cette deuxième pièce liminaire de l'œuvre est tout entière consacrée au récit de cette quête de sagesse qui s'achève par la découverte et la translation du livre. En toute logique, le récit devait apparaître déjà dans la version persane perdue. Enfin, Ibn al-Muqaffa' fait précéder le corps de l'œuvre d'une troisième pièce liminaire qui lui est, au moins en partie, directement imputable et qui consiste en une autobiographie fictive de Borzouyeh : à partir des événements de sa vie, le médecin livre, à la première personne, une réflexion désabusée sur la foi et sa fragilité, où résonne un scepticisme religieux qui pourrait bien, pour une bonne part, être davantage celui d'Ibn al-Muqaffa lui-même. C'est cette structure que l'on retrouve dans la première traduction de l'œuvre dans une langue occidentale, le Calila e Dimna castillan (introduction d'Ibn al-Muqaffa'; récit du voyage sapientiel de Borzouyeh-Berzebuey en Inde et de l'invention de l'œuvre ${ }^{6}$; récit autobiographique de Berzebuey). La traduction castillane ne reçoit pas de nouveau prologue de la main de son traducteur mais porte tout de même la marque de son promoteur dans l'explicit d'un des manuscrits conservés (ms. A) :

Aquí se acaba el libro de Calina et Digna. Et fue sacado de arávigo en latín, et romançado por mandado del infante don Alfonso, fijo del muy noble rey don Fernando, en la era de mill et dozientos et noventa et nueve años. El libro es acabado. Dios sea sienpre loado. (p. 355). 
Ici s'achève le livre le Calila e Digna. Il fut tiré de l'arabe en latin et mis en roman par ordre de l'infant Alphonse, fils du très noble roi Ferdinand, l'année de l'ère hispanique de 1299. Le livre est achevé. Que Dieu en soit loué pour toujours. et León) comme le commanditaire de la traduction. Malgré ce que laisse apparemment entendre cette déclaration, presque tous les critiques s'accordent aujourd'hui pour considérer que la traduction du Calila s'est faite directement à partir du texte arabe (ce qu'indique sa remarquable fidélité à la lettre du texte original). De même, on ne saurait déduire de l'explicit que la date de la traduction est 1299 de l'ère hispanique, soit 1261 de l'ère chrétienne, pour la bonne raison qu'Alphonse n'était plus infant en 1261 (il monte sur le trône ne 1252 , à la mort de son père). La critique considère que le manuscrit comporte une erreur et qu'il faut comprendre 1289, date renvoyant à 1251 de l'ère chrétienne ${ }^{7}$. Quelles que soient les circonstances précises de la traduction ${ }^{8}$, elle donne naissance à une version alphonsine de l'œuvre, que nous conservons à travers deux manuscrits. C'est cette version qui a permis, au tout premier chef, l'entrée en Espagne de contes orientaux en langue vernaculaire. On retrouve certains de ces contes, réélaborés ou croisés avec d'autres sources, sous la plume de grands auteurs du XIVe siècle tels don Juan Manuel et l'Archiprêtre de Hita. En revanche, la popularité européenne de la collection a été assurée par une autre version, le Directorium humanae vitae de Jean de Capoue (fin du XIIIe siècle ou début du XIVe siècle) qui dérive du Kalila wa Dimna arabe par l'intermédiaire d'une traduction en hébreu. À la fin du XVe siècle, le Directorium fait revenir le texte dans l'aire culturelle péninsulaire grâce à traduction castillane, imprimée pour la première fois à Saragosse en 1493, intitulée Exemplario contra los engaños y peligros del mundo, et qui donnera lieu à d'assez nombreuses éditions tout au long du XVIe siècle. Malgré l'existence de cette branche occidentale de l'œuvre, le nombre de traductions dans des langues européennes vernaculaires est resté très limité.

7 Il n'en va pas de même pour le Sendebar, dont la fortune littéraire a été assurée aussi bien par une branche orientale primitive que par une branche occidentale postérieure. Les origines orientales de l'œuvre sont mal connues. On ne sait toujours pas aujourd'hui si l'œuvre primitive a été écrite en sanskrit, en persan ou en hébreu. La théorie qui semble prévaloir met en parallèle la tradition du Sendebar et celle d'autres recueils d'origine orientale (notamment le Calila et le Barlaam e Josafat) pour considérer que l'œuvre a été produite en Perse à partir d'un matériau en grande partie indien. La difficulté provient du fait que nous ne conservons que des versions tardives dans chacune de ces traditions (la branche orientale se compose de versions en persan, hébreu, syriaque, grec, arabe - Les sept vizirs, intégrée aux Mille et une nuits - et castillane qui, toutes, dériveraient d'un intermédiaire arabe). Toutes ces versions ont entre elles des similitudes certaines, mais leurs contes varient ici et là, et elles tirent le plus souvent leur titre du nom du sage chargé de l'éducation du prince : Sindibad en arabe, Sindabar en hébreu, Syntipas en grec, Çendubete en castillan. En ce qui concerne la version castillane, le prologue révèle clairement qui a été son commanditaire, l'infant Fadrique, frère du roi Alphonse X, et, par lui, le livre se déclare directement issu d'une version arabe :

Plogo et tovo por bien que aqueste libro fuese trasladado de arávigo en castellano para aperçebir a los engañados e los asayamientos de las mugeres. Este libro fue trasladado en noventa e un años. (p. 64)

Il lui a plu et paru bon que ce livre fût traduit de l'arabe en castillan pour mettre en garde contre les tromperies et les manigances des femmes. Et ce livre a été traduit en l'année 91. 
De cette mention découle l'autre titre que l'on donne couramment au Sendebar: Libro de los engaños (Livre des tromperies). La date de la traduction (1291), une fois convertie dans le calendrier de l'Incarnation, donne 1253, soit deux ans après la date supposée de la traduction du Calila. Parce qu'il provient directement de l'arabe, le Sendebar castillan appartient à la branche orientale de la tradition. À cette arborescence primordiale de la tradition, s'oppose une branche occidentale, dite des Sept sages, issue de plusieurs traductions latines, réalisées dès le XIIe siècle, dont le fameux Liber de septem sapientibus à partir duquel ont été réalisées la plupart des versions vernaculaires européennes. La plus ancienne est la française (Les sept sages de Rome) mais il en existe dans une dizaine d'autres langues. Là encore, la branche occidentale n'exclut pas l'Espagne puisque, outre une version catalane, les Sept sages ont produit plusieurs versions castillanes tardives, dont la Novella de Diego de Cañizares dans la seconde moitié du XVe siècle (une adaptation de la Scala Coeli de Jean Gobi, mais à la manière du Décameron de Boccace $)^{9}$. D'une manière générale, les textes latins tels le Liber de septem sapientibus et d'autres (le Dolopathos sive de rege et septem sapientibus, de la fin XIIe siècle ou du début du XIIIe siècle) ont permis une diffusion immense du texte dans toute l'Europe médiévale et moderne. Une remarque s'impose cependant : dans la branche occidentale, la plupart des contes orientaux n'ont pas été transmis. Seuls 4 des 23 contes du Sendebar castillan se retrouvent dans la branche occidentale, ce qui révèle à quel point l'œuvre a été modifiée dans son passage de l'Orient à l'Occident. En fait, la transformation n'affecte pas profondément la structure essentielle, c'est-à-dire le cadre narratif. Celui-ci a joué son rôle de cadre rigide jusque dans les évolutions dues à la transmission du texte : les contes enchâssés dans le cadre ont été considérés comme interchangeables, ce qui explique la disparition de certains d'entre eux au cours de la transmission.

B. Les structures narratives et leur relation avec la dimension éthique1. Le Sendebar

9 Le Sendebar offre une forme assez stricte du schéma d'enchâssement que j'ai évoqué. Je vais en résumer la trame principale en insistant sur ses structures narratives. Le Sendebar relate l'histoire d'un roi, nommé Alcos, qui ne parvient pas à avoir d'enfant. Sur le conseil d'une de ses femmes, il prie instamment Dieu de lui donner un héritier et, peu après, la femme attend un enfant. Avant la naissance du prince, une première prédiction astrologique annonce au roi que son fils, à l'âge de vingt ans, entrera en conflit avec lui et se mettra ainsi en danger de mort. Au bout de quelques années, le roi confie l'éducation du prince à un sage de la cour, Çendubete, qui enferme l'enfant dans un palais dont les murs sont recouverts de tous les savoirs du monde. Là, le prince acquiert un savoir universel. Au moment où il s'apprête à rejoindre la cour de son père, il est l'objet d'une seconde prédiction astrologique : il devra s'abstenir de parler pendant sept jours, quoi qu'il arrive, ou bien mourir. Le prince y consent (dans la version castillane, le prince est appelé « infante ", infant, titre traditionnel des enfants de rois, mais dans ce contexte, le mot retrouve la coloration de son sens étymologique: «infans », celui qui ne parle pas encore $)^{10}$. Lorsqu'il arrive à la cour, une femme de son père tente de le séduire et lui propose en outre d'assassiner son père pour le supplanter sur le trône. Le prince s'y refuse. Alors, sa marâtre l'accuse publiquement de tentative de viol. Comme l'infant ne prononce pas un mot pour nier le crime et se défendre, le roi le condamne à mort. Cependant, pendant les sept jours que dure le silence du prince, chacun des sept conseillers du roi intervient pour obtenir sa grâce : chaque jour, un conseiller relate deux contes, ce qui permet d'infléchir la sentence du roi. Mais, dès le lendemain, la marâtre intervient à son tour et, par la narration d'un conte, obtient la condamnation de l'infant, 
à nouveau annulée par les contes d'un nouveau conseiller. Et ainsi de suite. Ce sont ainsi 18 contes qui sont relatés par les conseillers ou la marâtre et qui, chaque jour, font s'inverser la sentence du roi et retardent la mise à mort de l'infant. À l'issue des sept jours de silence forcé, l'infant retrouve la parole et devient à son tour le narrateur de contes. Par ses récits, l'infant n'accuse pas directement sa marâtre, mais se contente de manifester son savoir et de faire la preuve son discernement, ce qui lui donne davantage de crédibilité qu'une révélation directe de la vérité. À l'issue du cinquième conte relaté par l'infant, le roi décide d'exécuter sa mauvaise femme et c'est sur cette exécution que se clôt le récit.

Dans le Sendebar, tous les récits, quel que soit leur narrateur, sont adressés au roi et à sa cour (les courtisans sont présents implicitement, rarement explicitement). Le roi, comme dépositaire du pouvoir, est le destinataire qu'il faut convaincre pour qu'il revienne sur sa décision de tuer ou d'épargner son fils. Or, tous les récits atteignent immanquablement leur but: le roi modifie chaque jour sa sentence. Le sujet récepteur n'a donc aucune épaisseur argumentative. Lui qui incarne le plus haut pouvoir politique et, en particulier, le pouvoir de vie et de mort sur ses sujets, se contente de prendre acte de la moralité du conte en la traduisant en termes de décision officielle, selon une formule figée :

E el Rey mandó matar su fijo / E mandó el Rey que non matasen su fijo.

Et le roi ordonna de tuer son fils / Et le roi ordonna que l'on ne tuât pas son fils.

11 En conséquence, les critiques ont souvent souligné le statut particulier qui, dans le Sendebar, est conféré à la parole. La parole équivaut à l'action mais il convient sans doute de préciser cette équivalence qui peut apparaître ambivalente. María Jesús Lacarra a pu caractériser la structure narrative du Sendebar comme un enchâssement narratif parfait, au sens où chacun des contes modifie le cours de l'intrigue du cadre narratif ${ }^{11}$. Selon ce point de vue, la parole est action : le destinataire qu'est le roi ne lui oppose jamais aucune résistance et se contente de l'avaliser pour qu'elle prenne force de loi. Le récit enchâssé joue à plein son rôle de preuve et son efficacité est totale. Outre la réaction univoque du roi, d'autres éléments le montrent. En particulier, le septième et dernier jour, la femme ne propose pas au roi de récit mais une mise en scène de son suicide :

E quando vino al seteno día, dixo: -Si este mançebo oy non es muerto, oy seré descubierta. E esto dixo la muger : -Non ay ál sinon la muerte. Todo quanto aver pudo diolo por Dios a pobres, e mandó traer mucha leña e asentóse sobre ella. E mandó dar fuego enderredor, e dezir que se quería quemar ella. E el Rey, quando esto oyó, ante que se quemase, mandó matar al moço. (p. 218).

Et quand vint le septième jour, elle se dit: «Si ce jeune homme n'est pas mort aujourd'hui, je serai aujourd'hui découverte». Et voici ce que la femme dit: «Il ne me reste que la mort ». Tous les biens qu'elle put rassembler, elle les donna en aumône aux pauvres. Puis elle fit apporter un tas de bois sur lequel elle s'assit. Elle ordonna que l'on y mît le feu tout autour et que l'on rapportât qu'elle voulait être brûlée. Le Roi, quand il entendit cela, avant qu'elle ne fût brûlée, ordonna que l'on tuât son fils.

Ici un chantage au suicide se substitue à la narration, ce qui révèle que tous les autres récits ne sont pas censés porter une force de conviction de nature essentiellement différente. Comme le chantage, argument forçant, le récit exemplaire prétend imposer arbitrairement une relation logique spécieuse parce que posée de l'extérieur comme indiscutable : la relation entre deux situations particulières dont on estime que l'une doit s'aligner sur l'autre en vertu d'un principe général. 

reporter une mise à mort. Ce danger de mort concerne chacun des narrateurs de contes. La vie de l'infant n'est pas la seule en jeu. La femme du roi sait parfaitement que si elle ne parvient pas à convaincre son époux de tuer l'infant avant les sept jours fatidiques, celuici pourra révéler la vérité et que c'est elle qui en subira les conséquences. Dès le moment où l'infant refuse d'entrer dans sa machination, il est précisé dans le récit :

Después que esto ovo dicho, entendió ella que sería en peligro de muerte e dio bozes e garpiós' e començó de mesar sus cabellos. E el Rey, quando esto oyó, mandóla llamar e preguntóle que qué oviera. E ella dixo : -Este que dezides que non fabla me quiso forçar de todo en todo, e yo non lo tenía a él por tal (p. 75).

Après qu'il eut dit cela, elle comprit qu'elle allait être en danger de mort. Elle poussa des cris et se griffa et se mit à s'arracher les cheveux. Le roi, lorsqu'il entendit cela, la fit appeler et lui demanda ce qu'il lui était arrivé. Et elle dit: «Celui dont vous dites qu'il ne parle pas a voulu me violer du tout au tout, et moi je le tenais pas pour quelqu'un de cette sorte».

L'accusation proférée par la femme est donc avant tout motivée par son désir de garder la vie sauve. De même, les conseillers qui interviennent auprès du roi pour défendre l'infant n'agissent pas de façon complètement désintéressée. Tout en remplissant leur devoir, ils savent que leur vie est également en jeu dans le débat :

Después que vieron qu'el Rey mandava matar su fijo, a menos de su consejo, entendieron que lo fazía con saña porque creyera su muger. Dixieron los unos a los otros:-Si a su fijo mata, mucho le pesará e después non se tornará sinon a nos todos, pues que tenemos alguna razón atal por que este infante non muera. (p. 76). Quand ils virent que le roi ordonnait la mort de son fils sans leur demander conseil, ils comprirent qu'il le faisait sous l'emprise de la colère parce qu'il avait cru sa femme. Ils se dirent les uns aux autres : "S'il tue son fils, il s'en repentira fort et, ensuite, c'est contre nous qu'il se retournera parce que nous avons des arguments pour empêcher la mort de l'infant ".

Dire, c'est agir et, dans ces conditions, le récit acquiert une épaisseur temporelle : il ne vaut pas seulement pour son énoncé, mais pour son énonciation qui, en se déployant, occupe le temps et remplace le recours direct à une action d'un autre type. Dans ces conditions, l'attitude univoque du destinataire qu'est le roi devient équivoque, puisque toute narration lui semble valide et qu'il ratifie en termes de loi des moralités qui s'opposent les unes aux autres. Si le monarque accepte tout et son contraire, l'équivalence entre la parole et l'action en vient à signifier pour lui l'absence d'action, la remise au lendemain perpétuelle, l'oscillation devant les arguments contradictoires qui lui sont proposés. La parole est moins efficace comme énoncé que comme énonciation. Du point de vue du destinataire, il semble que c'est l'acte même de dire (l'énonciation) qui légitime l'énoncé. Le contenu éthique des contes, de ce point de vue, est mis à distance. Les contes de la femme, par leur efficacité pragmatique, valent autant que ceux des conseillers alors que les thèses qu'ils défendent sont opposées et que leurs rôles respectifs sont moralement marqués dans le récit-cadre (la marâtre criminelle s'oppose aux bons conseillers). C'est sans doute plus qu'un hasard ou qu'un accident si, dans l'histoire de la transmission de l'œuvre, le conte «Senescalcus » (le neuvième de la version castillane), attribué à un conseiller dans la tradition orientale, devient un conte de la marâtre dans la tradition occidentale ${ }^{12}$ : la matière narrative du conte a moins d'importance que l'énonciation qui le prend en charge pour affirmer son efficacité. Dans certaines conditions, les contes sont donc interchangeables pourvu qu'ils permettent l'affirmation énonciative d'un narrateur. 

confirme cette mise à distance de la dimension éthique, si l'on entend par là un « contenu » moral: il ne s'agit plus de prouver une thèse, quelle qu'elle soit, mais, tout simplement, de s'affirmer par la parole. De façon assez surprenante, l'infant qui reprend la parole après son silence imposé n'accuse pas directement sa marâtre. Par le conte 19, «Lac venetatum », il prétend même montrer que la question de la culpabilité n'est pas essentielle puisque toute action accomplie l'est toujours en vertu d'une destinée qui dépasse les responsabilités individuelles en en faisant les instruments de sa réalisation :

El Infante dixo :-Ninguno destos non ovo culpa, mas açertóseles la ora en qual avién a morir todos.

L'infant dit: «Aucun d'entre eux n'était coupable, mais c'est que l'heure de leur mort à tous était arrivée ».

Transposée dans l'économie de l'exemplarité, ce dépassement des enjeux partisans se traduit par la disparition d'une thèse à défendre. Le but affiché de l'infant narrateur se réduit à la manifestation de son propre savoir :

El Infante se levantó e dixo :-Dios loado, que me feziste ver este día e esta ora, que me dexeste mostrar mi fazienda e mi razón. Menester es de entender la mi razón, que quiero dezir el mi saber, e yo quiérovos dezir el enxenplo desto. (p. 138)

L'infant se leva et dit : "Sois loué, mon Dieu, toi qui m'as permis de voir ce jour et cette heure et qui m'a laissé manifester mon aventure et mon propos. Il vous faut comprendre mon propos, car je veux vous dire mon savoir, et je veux vous en donner l'exemple. »

L'exemple introduit par cette déclaration, le conte «Puer 4 annorum», ainsi que le suivant « Puer 5 annorum », mettent en scène le savoir prodigieux de deux jeunes enfants dans lequel est censé se refléter directement le savoir de l'infant. L'exemplarité du récit ne s'applique donc plus à un engagement rhétorique explicite qu'il s'agirait de défendre, mais au prestige même de celui qui parle. Or, c'est seulement à l'issue de ce processus de mise à distance de la moralité explicite dans le conte que la décision du roi sera sans appel et que le récit, enfin, se traduira en ferme décision de justice, manifestation définitive de sa dimension éthique. D'où ce paradoxe: le conte ne devient pleinement efficace du point de vue éthique que lorsqu'il s'affranchit explicitement de toute moralité explicite. Ce paradoxe révèle que l'efficacité rhétorique et matérielle du récit ne dépend qu'accessoirement de l'énoncé de la moralité qu'il est censé fonder ou corroborer. Dans ce cas, le récit n'a pour but que de manifester le prestige du narrateur. Plus que l'énoncé, c'est donc l'énonciation (du récit et, éventuellement, de sa moralité) qui assoit par ellemême la portée pragmatique du discours et lui donne son caractère indiscutable. On peut contester un énoncé, mais pas une pure énonciation, à moins d'en arriver à des arguments ad hominem ou à d'autres attaques qui mettraient directement en cause la légitimité du narrateur à prendre la parole et qui couperaient à la racine le prestige dont il s'investit lui-même. C'est ainsi que l'infant triomphe de son ennemie et la fait condamner: non en prétendant faire de son récit le rouage d'un raisonnement démonstratif, mais en exploitant en lui une vertu d'auto-légitimation, issue de sa pure énonciation.

2. Le Calila e Dimna

19

Dans le Calila e Dimna, on trouve également une valorisation de l'énonciation par rapport à l'énoncé, peut-être encore plus radicale, mais elle passe par des procédés différents qui, par certains aspects sont très voisins et, par d'autres, opposés. 
20 Le Calila, outre les pièces liminaires, se compose de 16 chapitres qui sont des récits autonomes (sauf les deux premiers qui forment un diptyque). L'élément unificateur de ces 16 récits n'est pas exactement un récit-cadre comme celui du Sendebar, mais un dialogue entre un roi et son conseiller désigné comme un philosophe ${ }^{13}$. Le roi demande à son conseiller qu'il lui donne un exemple pouvant illustrer telle ou telle attitude humaine. Le philosophe entreprend alors la narration, qui occupe tout un chapitre. La fin du chapitre est parfois marquée par un retour au dialogue principal qui exprime, dans ce cas, les éléments d'une morale. Ce dialogue qui englobe tous les chapitres pourrait être considéré comme un récit-cadre, puisqu'il fait logiquement intervenir un narrateur pour introduire les répliques des deux personnages, mais il s'agirait alors d'un récit minimal qui, en outre, offre très peu de variété et se montre le plus souvent redondant face aux moralités que chaque conte énonce déjà de manière interne, par la bouche d'un de ses personnages. On a plutôt l'habitude de désigner comme récit-cadre chacun des récits relatés par le philosophe au roi et les considérer comme des récits de niveau 1 (alors qu'en toute rigueur, leur narrateur, le philosophe, est intradiégiétique).

21 C'est à l'intérieur de ces récits-cadres que viennent s'insérer des contes de niveau 2 et, dans un petit nombre de cas, des contes de niveau 3, par une duplication de l'enchâssement que María Jesús Lacarra a baptisé procédé « de cajas chinas » ${ }^{14}$ ( de boîtes chinoises ») que l'on a coutume plutôt de désigner en français par l'image des poupées russes.

Dans leur grande majorité, ces 16 récits-cadres mettent en scène des animaux doués de parole, ce qui est le cas aussi de la plupart des contes enchâssés, alors que tels récits sont exceptionnels dans le Sendebar. Je prendrai seulement l'exemple des chapitres III et IV qui sont les deux premiers des 16 chapitres déjà évoqués. Ces deux chapitres sont les seuls du recueil à fonctionner comme les deux volets d'un même récit-cadre qui a donné son nom à l'ensemble de l'œuvre puisque Calila et Dimna sont les noms de deux de ses personnages. Ce sont deux chacals, ou loups cerviers, qui vivent à la cour du roi lion sans y occuper une position particulièrement enviable. Calila est satisfait de son sort médiocre mais Dimna ne pense qu'à monter dans la hiérarchie sociale. Il voudrait devenir le conseiller du lion. Une occasion inespérée se présente à lui : un bœuf, nommé Sençeba, s'établit non loin de là et Dimna se rend compte que le lion, sans oser le dire, a peur de ses beuglements. Dimna parvient à rassurer le roi, devient son conseiller et, par son entremise, le bœuf Sençeba entre à la cour. À la peur du lion envers le bœuf succède alors une grande amitié : Sençeba devient le confident du roi et supplante Dimna qui se trouve relégué à une place inférieure. Furieux de voir le piètre résultat de ses bons offices, Dimna projette d'éliminer le bœuf et, pour cela, en bon intrigant, travaille à le brouiller avec le lion. Le récit est constamment ponctué de dialogues, notamment entre Calila et Dimna. Calila conseille à Dimna de renoncer à ses projets dictés par l'ambition et, lorsqu'il voit que c'est inutile, lui conseille la plus grand prudence. Des contes sont relatés par l'un et par l'autre pour expliquer ou défendre son point de vue. Dans son projet de saper l'amitié du lion et du bœuf, Dimna a systématiquement recours à la narration de contes. Sençeba lui répond de la même façon. Dans cette intrigue à quatre personnages, seul le lion n'est jamais narrateur. Dimna fait le lien entre tous les personnages : il adresse ses contes aux trois autres personnages et tous les contes dont il n'est pas narrateur lui sont adressés. $\mathrm{Au}$ terme de son entreprise, Dimna parvient à semer la zizanie entre les deux amis qui finissent par se battre à mort. Le bœuf est tué par le lion et Dimna retrouve sa dignité perdue $^{15}$. Ainsi se termine l'histoire dans la version indienne du Panchatantra et, sans 
doute aussi, dans la version en persan que nous n'avons pas conservée. Ibn al-Muqaffa', l'auteur du texte arabe, sans doute parce qu'il n'a pas été satisfait de cette fin peu édifiante, a ajouté un chapitre de son cru: le chapitre IV, que l'on retrouve dans la version castillane sous le titre: «De la pesquisa de Dimna» («Du procès de Dimna»). Dans cette suite, l'ordre moral est rétabli puisque Dimna est accusé d'avoir trahi le lion son roi et, au terme d'un long procès où il ne manque pas de se défendre à coups d' exempla, finit par être condamné à mort et exécuté, même si des ambiguïtés demeurent ${ }^{16}$.

La structure narrative du Calila, par opposition à celle du Sendebar, a été parfois qualifiée d'«imparfaite»: aucune narration n'y est nécessaire du point de vue structurel, contrairement à ce que prévoyait le programme narratif rigide et clos du Sendebar - du moins dans la phase des sept jours de silence de l'infant. Il s'agit ici d'une structure ouverte où le conte enchâssé n'est pas un rouage assigné à une place déterminé par avance pour que fonctionne l'ensemble du mécanisme narratif. Le rapport du conte à son récit-cadre apparaît, en ce sens, beaucoup plus lâche : la narration des contes n'est pas nécessairement le moteur de l'intrigue principale. Le conte est toujours un argument, au même titre que les sentences ou similitudines, mais il se partage entre une fonction explicative (ou illustrative) et une fonction probatoire. Même dans le cas du procès de Dimna, l'échange des contes n'est pas déterminant pour établir la culpabilité de Dimna : la preuve, si preuve il y a, vient de l'extérieur et l'efficacité rhétorique des récits relatés par Dimna, même si elle ne le sauve pas de la mort, n'est entamée par aucune réfutation recevable. Tout se passe comme si la parole, formellement irréfutable, ne parvenait pas à se réaliser pleinement dans l'action.

En ce sens, on notera un paradoxe spécifique aux contes du Calila : la parole du narrateur est le plus souvent inopérante sur son destinataire. Alors que les contes du Sendebar parvenaient à convaincre à tout coup, ceux du Calila, dans la grande majorité des cas, ne parviennent pas à infléchir l'attitude de leur récepteur. La réaction incrédule du récepteur s'exprime même par une formule qui, dans l'œuvre, apparaît quasi figée: « Entendido he lo que dexiste, mas... » («J'ai compris ce que tu as dit, mais... »). Par cette formule, le destinataire reconnaît l'intérêt exemplaire du conte mais s'empresse de nier l'opportunité de son application dans le cas particulier qui est le sien. On chercherait en vain une logique dialectique dans cette reconnaissance ambiguë de la valeur du conte par son récepteur. Elle révèle plutôt le fossé qui existe entre le conseil et sa mise en application, ou entre la parole et l'action, alors que ces dernières tendaient à se confondre dans le Sendebar. Si l'énonciation est au centre du processus exemplaire du Calila, ce n'est donc pas parce qu'elle permet d'éprouver le pouvoir de la parole. Au contraire, sa valorisation permet d'explorer la fracture, souvent porteuse d'ironie, qu'il existe entre ce que disent les personnages et ce qu'ils font. Comme dans le Sendebar, et même à plus forte raison, les contes du Calila ne livrent tout leur sens que dans les correspondances qui les lient à leur contexte: dans ce cas, ces correspondances, on le verra, produisent de subtils glissements et ce que l'on pourrait appeler une démultiplication du sens.

II. Deux études de casA. Le conte « Leo » du Sendebar1. Structure d'ensemble

I. L'adultère évité : être sûr de son fait avant de se lancer dans une action ${ }^{17}$

1. Le roi aperçoit une femme et veut la posséder

2. Celle-ci ne refuse pas, mais pose des obstacles qui lui font gagner du temps :

a) la présence de son mari : le roi envoie le mari dans une armée 
b) le temps nécessaire à sa toilette

3. La femme laisse au roi un livre de lois, dans lequel il lit que l'adultère est interdit

4. Le roi renonce à son projet et s'en va.

Mais il oublie ses pantoufles sous le lit de la femme, ce qui déclenche une deuxième séquence.

II. Les indices trompeurs : être sûr de son fait avant de se lancer dans une interprétation

1. Le mari, de retour chez lui, découvre les pantoufles du roi et, croyant que ce dernier a possédé sa femme, ne s'approche plus d'elle.

2. La femme, qui ne comprend pas, s'en plaint à ses parents qui, à leur tour, obtiennent que le mari leur révèle ses scrupules.

3. Les parents de la femme et le mari vont voir le roi et, se plaignant à lui sous couvert d'une allégorie, obtiennent, dans les mêmes termes, une réponse de sa part : il n'a pas commis l'adultère avec la femme.

4. Le mari demande à sa femme de raconter toute l'histoire et comme sa version concorde avec celle du roi, il la croit et lui fait par la suite davantage confiance qu'auparavant.

La moralité est exprimée d'emblée par le conseiller :

Señor, non deve fazer ninguna cosa el omne fasta que sea çierto della

Seigneur, l'homme ne doit rien faire avant d'être sûr de son fait

L'exemplarité fonctionne dans la tension entre l'universel et le particulier - ce qui est une de ses caractéristiques constantes, quelle que soit sa forme -, mais dans les œuvres dotées d'un récit-cadre comme le Sendebar et la Calila, cette tension se manifeste de façon particulière : face à la formule sentencieuse de la moralité, dont la formulation renvoie à l'universel, on trouve deux situations particulières, celle des personnages du récit-cadre et celles des personnages du conte enchâssé. Contrairement à d'autres œuvres où les exempla ou fables proposent une moralité qui est censée s'extraire du récit, les narrateurs des contes du Sendebar et du Calila insèrent la moralité universelle à la jonction entre deux récits et la colorent donc de leur double interaction (qui n'est pas nécessairement redondante).

2. Premier volet du conte

40 Le conte offre une structure en deux volets, dont le premier apparaît doté d'une certaine autonomie narrative: sans l'oubli des pantoufles du roi, le récit pourrait se clore et correspondrait parfaitement à la moralité exposée. Cette première séquence du récit pourrait se suffire à elle-même du point de vue narratif aussi bien que du point de vue éthique. Son schéma narratif reprend le schéma bien connu de l'histoire de David et Bethsabée ${ }^{18}$, mais en inversant l'issue du projet du roi ${ }^{19}$. Le désir adultère du roi est un élément perturbateur qui trouble la stabilité d'un couple, mais cette stabilité sera rétablie et même renforcée à la fin du conte. Dans la première séquence, l'adultère est évité grâce à une ingénieuse astuce de la victime. La femme emploie un stratagème éminemment subversif, puisque, sans s'opposer directement au désir du roi, elle lui donne un livre de lois qui fera fléchir sa volonté. À ce moment de la narration, la correspondance de personnages et de situations entre le conte enchâssé et le récit-cadre est assez transparente, du moins selon une lecture « initiale ».

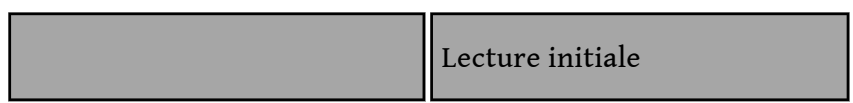




\begin{tabular}{|l|l|}
\hline Roi & Roi Alcos \\
\hline \hline Femme & Infant / Conseiller \\
\hline \hline Livre de lois & Moyen utilisé par le conseiller \\
\hline \hline Mari & $\varnothing$ \\
\hline Parents de la femme & $\varnothing$ \\
\hline \hline Allégorie de la terre et du lion & $\varnothing$ \\
\hline
\end{tabular}

41 a) D'emblée, la présence d'un roi dans le conte semble offrir au roi Alcos (qui est destinataire du conte) une image de lui-même.

42 b) En outre, dans les deux cas, le roi est sur le point de commettre une action injuste et irréparable. L'adultère avec la femme, dans le conte, renvoie à la condamnation à mort de l'infant dans le récit-cadre

43 c) La femme du conte, en tant que victime soumise au caprice du monarque, représente donc l'infant. De plus, le consentement apparent de la femme - «lo que tú quesieres, quiérolo yo» («tout ce que tu veux, je le veux aussi ») - peut rappeler le silence de l'infant, qui ne peut opposer par lui-même aucune objection à la condamnation dont il est l'objet.

44 d) Mais bien qu'elle soit victime, la femme joue aussi pour le roi le rôle d'une conseillère. Sans lui donner directement son avis, elle lui tend le livre qui le fera se raviser: le conseiller du roi construit donc la figure de la femme comme une figure de lui-même.

e) Le livre appartient au mari absent et en est un substitut : le donner à lire au roi retarde le moment de l'adultère et, en même temps, introduit symboliquement la présence du mari entre elle et le roi. On reconnaît là la fonction attribuée à l'ensemble du conte luimême : retarder la mise à mort de l'infant tout en fournissant à son destinataire, le roi Alcos, des arguments pour qu'il modifie sa sentence. Le livre évoqué dans le conte est donc, en abyme, une image du conte lui-même. Bien que son contenu ne soit pas directement rapporté dans le texte, le livre offre au roi, en miroir, une image de sa propre situation. Non seulement il lui rappelle que l'adultère est défendu, mais il ne se limite pas à cet avertissement légal. Le livre, d'ailleurs, ne semble pas prévoir de punition pour les hommes adultères, mais pour les femmes : « de cómmo escarmentavan a las mugeres que fazían adulterio » (« par lesquels ils châtiaient les femmes qui commettaient l'adultère »). Ce n'est pas essentiellement la perspective d'un châtiment légal qui fait le roi douter et se raviser, mais le fait que la loi émane de l'instance royale qu'il représente lui-même : « leyes e juizios de los reyes » (« lois et jugements des rois»). En tant que source de la loi, le roi se doit de la respecter au tout premier chef $^{20}$. Du même coup, le livre, normalement destiné aux jugements des sujets du roi, devient un véritable " miroir des princes » et provoque chez le monarque ce sentiment de honte («vergüenza ») qui le fait renoncer à l'adultère ${ }^{21}$. Si le livre représente le conte, il représente aussi tout « miroir des princes » et, en particulier, le Sendebar dans son ensemble. D'ailleurs, le Sendebar, s'il n'est pas un recueil de lois destiné à punir les femmes adultères, est bien un livre destiné à dénoncer les méfaits de la gent féminine, comme l'annonce clairement le prologue. Par la veine 
misogyne qu'il exploite et par le statut d'œuvre politique qu'il se donne, le recueil tout entier semble figuré dans ce livre providentiel. Grâce à lui, un roi oublieux de la loi renonce à l'adultère; grâce au conte, un roi impulsif renonce à l'infanticide; grâce au Sendebar, un éventuel lecteur royal pourra donc éviter de commettre quelque crime.

Dans « Leo », premier conte du Sendebar, est mise en scène la bonne utilisation éthique de l'œuvre à venir. En ce sens, «Leo » joue aussi le rôle d'un mode d'emploi qui est censé permettre une lecture adéquate de tous les contes et une exploitation convenable de ces contes en termes éthiques. Sous le coup de la moralité annoncée dès l'abord (« non deve fazer ninguna cosa... »), c'est bien tout utilisateur du livre qui est désigné : le conte et le livre sont précisément les instruments qui permettent au lecteur d'être sûr de son fait et d'agir en connaissance de cause.

Ce premier volet du conte pointe donc le prolongement éthique qui doit couronner la lecture du récit. Dans ses rapports à son récit-cadre, le conte « Leo " présente à cet effet une grande transparence interprétative fondée sur une correspondance entre les actants. La similitude entre le roi Alcos et le roi du conte est l'axe de l'interprétation. Même dans le second volet du conte, cette similitude peut se maintenir: le roi y entend le récit allégorique que lui racontent les parents de la femme : comme le roi du récit-cadre, il assume le rôle de narrataire. Pourtant, ce système de correspondance apparait instable pour deux raisons :

48 a) Les personnages de l'infant et du conseiller sont tous deux représentés par la figure de la femme dans le conte.

b) Aucun personnage, dans le récit cadre, ne saurait correspondre à la figure du mari, pas plus qu'aux personnages des parents.

De fait, cette correspondance va être remise en cause dans le second volet du conte.

3. Second volet du conte

51 L'adultère entre le roi et la femme n'a pas été consommé. Pourtant, le roi a oublié ses pantoufles sous le lit de la femme (tout près du lieu qui symbolise l'intimité des époux). Le roi a laissé par mégarde un indice du crime qui n’a pas eu lieu : il a créé les apparences d'un événement inexistant. Le mari, en interprétant la présence de cet indice, en déduit la culpabilité de sa femme et se refuse à toute relation conjugale. Le mari se trompe : c'est par une interprétation hâtive qu'il accorde un sens au signe qu'il a relevé. Son attitude contredit exactement la moralité annoncée du conte, dont il offre un parfait exemple $a$ contrario. L'exemplarité du conte est alors soumise à deux réorientations :

a) Les rôles sont redistribués dans cette seconde lecture que nous appellerons « finale ».

\begin{tabular}{|l|l|l|}
\hline & I. Lecture initiale & II. Lecture finale \\
\hline \hline Roi & Roi Alcos & $\varnothing$ \\
\hline \hline Femme & Infant / Conseiller & Infant \\
\hline \hline Livre de lois & Moyen utilisé par le conseiller & $\varnothing$ \\
\hline \hline Mari & $\varnothing$ & Roi Alcos \\
\hline
\end{tabular}




\begin{tabular}{|l|l|l|}
\hline Parents de la femme & $\varnothing$ & Conseiller \\
\hline \hline Allégorie de la terre et du lion & $\varnothing$ & Moyen utilisé par le conseiller \\
\hline
\end{tabular}
introductive figée ( Oí dezir », «J'ai entendu dire»), le récit est prétendument doté d'une certaine véracité puisqu'il est allégué, ce qui constitue une forme minimale d'autorité2 ${ }^{2}$. En revanche, le récit que s'apprêtent à raconter les parents de la femme est présenté par eux au mari comme une fiction construite à partir des faits réels :

démoslo enxenplo de aqueste fecho de la muger, e non le declaremos el fecho de la muger.

faisons-lui un exemple de cette histoire de la femme sans lui révéler l'histoire de la femme.

On ne saurait trouver une définition plus exacte de la fiction allégorique, soit un récit construit tout exprès pour traduire les faits préexistants en des termes voilés ou métaphoriques.

\begin{tabular}{|l|l|}
\hline Terre & Femme \\
\hline \hline Donateurs de la terre & Parents de la femme \\
\hline \hline Laboureur de la terre & Mari \\
\hline \hline Labour & Relation conjugale \\
\hline
\end{tabular}




\begin{tabular}{|l|l|}
\hline Lion & Roi \\
\hline \hline Trace du lion & Pantoufles du roi comme indice de sa visite \\
\hline
\end{tabular}
dans le texte aucune justification explicite. Pourquoi les parents de la femme n'adressentils pas directement leur plainte au roi? De ce point de vue, plusieurs explications pourraient sans doute être avancées, et parmi elles, celle qui prend en compte la majesté dont est revêtu le roi : les plaignants craignent d'accuser le roi à tort et, par respect pour sa majesté, choisissent cette forme indirecte et cryptée. Cependant, le texte ne dit rien de cela et ne présente pas les choses en ces termes. Quel que soit son degré de vraisemblance, le recours à l'allégorie par les personnages n'est justifié dans le texte que par l'épreuve interprétative qu'il implique :

si él entendido fuere, luego lo entenderá

s'il est intelligent, il le comprendra aussitôt.

Tout se passe comme si l'allégorie était un jeu gratuit, seulement destiné à éprouver l'intelligence de son destinataire et sa capacité à interpréter. L'interprétation erronée du mari, qui a vu l'adultère là où il n'y en avait pas, ne peut être dépassée que par un autre effort interprétatif, qui prenne en compte l'ensemble des faits. Les différents destinataires de l'allégorie (le roi du conte, le roi du récit-cadre et le lecteur lui-même), qui ont tous une vision d'ensemble des faits, peuvent résoudre l'énigme sans difficulté. Le roi du conte émet une réponse en utilisant le code même de l'allégorie qui lui a été proposée et, par le biais d'une fiction partagée, rétablit la vérité. Le mari, quant à lui, pour que la vérité soit définitivement rétablie, devra en outre demander à sa femme de lui faire le récit des événements. La vérité jaillit de la concordance des signes :

creyóla por las señales quel' dixiera el Rey

il la crut en raison des détails que lui avait donnés le Roi

61 La première interprétation du mari, fondée sur un indice unique, a été dépassée au profit d'une autre version des faits, recevable comme vérité parce qu'elle prend en compte la totalité des signes. De l'erreur à la vérité, le passage s'est fait par un recours, apparemment gratuit, à la fiction.

Pour les destinataires extérieurs au conte (le roi Alcos et le lecteur) cet exercice interprétatif est aussi une invitation à participer activement à la production du sens, quels que soient les récits soumis à leur interprétation, même si en ce qui concerne l'interprétation, la mise en abyme ne saurait être parfaite.

4. Une mise en abyme imparfaite

63 Les deux récits, s'ils diffèrent dans leur statut, comme nous l'avons vu, diffèrent aussi dans le type d'interprétation qu'ils suscitent. Contrairement au conte :

64 a) L'allégorie n'est pas une pièce autonome : sans le récit qui la précède, elle n'aurait aucun sens. Elle n'est qu'un prolongement ou une reformulation d'un récit logiquement antérieur.

b) Son code interprétatif est unique et transparent: il n'y a aucune possibilité de lui trouver une seconde interprétation en modifiant la correspondance entre les actants. Elle n'offre aucun jeu interprétatif. Dans le contexte qu'elle se choisit, son sens est univoque. 
66 Le conte, quant à lui, est une pièce détachable (un exemplum séparable de son contexte, même si son sens dépend de ce contexte) et même sécable (le premier volet du conte pourrait fonctionner de manière autonome). Enfin et surtout, son sens n'est pas univoque, même une fois qu'il a été inséré dans un récit-cadre et qu'il a été flanqué d'une moralité explicite.

Dans ces conditions, la mise en relation directe du conte «Leo » et de l'allégorie qu'il contient peut susciter plusieurs interrogations. En particulier, nait une question: le narrateur suggère-t-il à son récepteur qu'il faut aligner le mode d'interprétation du conte sur le mode d'interprétation de l'allégorie ? Si tel est le cas, le conseiller suggère à son roi que son propre conte n'a qu'une seule interprétation valable. Dans la partie centrale du Sendebar, où les conseillers du roi et la marâtre rivalisent d'exemples pour sauver ou faire condamner l'infant, les différents narrateurs s'efforcent de gommer les éventuelles ambiguïtés des contes pour les réduire à une moralité immédiatement efficace en termes argumentatifs. Ils posent en idéal un encadrement très strict du conte par l'appareil argumentatif, ce qui répond à l'urgence de la situation : de l'efficacité des contes dépend le sort de l'infant. L'influence de la narration sur le comportement du récepteur est d'ailleurs à la mesure de cet idéal : le roi Alcos, chaque jour, se laisse fléchir et modifie sa sentence.

Pourtant, en ce qui concerne le conte « Leo », les ambiguïtés sont loin d'être levées. Outre le flottement entre les deux grilles interprétatives que nous avons relevées, une ambiguïté centrale ne saurait disparaître, même si l'on déploie pour cela un appareil argumentatif très rigide: la femme, dans le conte, est une figure de la vertu et de l'innocence. Or, dans le récit-cadre, l'un des buts du conseiller qui raconte «Leo » est précisément de confondre la marâtre de l'infant qui l'a accusé et veut le faire condamner. María Jesús Lacarra, relevant cette ambiguïté, parle d'une «incohérence " ponctuelle de ce récit ${ }^{23}$. Pour ma part, je me demande plutôt si les paradoxes de ce type ne sont pas le signe d'une instabilité fondamentale de tous les récits exemplaires. C'est ce que je me propose de montrer à partir d'un conte du Calila e Dimna.

B. Conte des « tittuy » dans le Calila1. Structure d'ensemble

Ce conte peut paraitre curieux à divers titres ${ }^{24}$. Tout d'abord, ses personnages peuvent paraître mystérieux. Si l'on peut identifier les « tittuy » comme des oiseaux marins, peutêtre des pluviers ${ }^{25}$, il est plus ardu de cerner la nature de l'énigmatique personnage qu'est «l'intendant de la mer» (« el mayordomo de la mar»). Il semble que ce dernier soit un vestige du polythéisme indien qui marquait la version primitive du texte : dans la version sanskrite, la mer apparaît sous les traits d'un dieu, l'oiseau Garuda, et, au fil de la tradition, cette déification a laissé la place à une personnification moins directe de la mer ${ }^{26}$. Cependant, si le conte apparaît curieux, c'est surtout par les ambiguïtés profondes qui caractérisent les rapports entre le récit et sa dimension éthique : le chemin qui va du conte à la moralité qu'il propose n'est univoque qu'en apparence.

70 Les structures narratives du conte se fondent sur le procédé des «cajas chinas » déjà évoqué, soit à une mise en abyme de la narration. Le récit-cadre est celui de l'ensemble du chapitre III, ou récit " du lion et du bœuf », qui met en scène également les deux chacals qui ont donné leur nom à l'œuvre tout entière. Dans ce passage, Dimna raconte au bœuf Sençeba l'histoire des deux pluviers (première insertion). Enfin, à l'intérieur de cette histoire, la femelle du pluvier raconte au mâle le conte de la tortue et des deux canards (deuxième insertion). La structure d'ensemble présente donc trois niveaux narratifs, 
auxquels on pourrait, en toute rigueur, ajouter un autre niveau plus fondamental que tous les autres, puisque le récit-cadre s'insère à son tour dans un dialogue entre le roi et le philosophe. Contrairement au conte «Leo » du Sendebar, l'histoire du niveau le plus profond, «La tortue et les deux canards ", est tout à fait autonome et de fait, elle l'a été dans la tradition ${ }^{27}$. Mais l'autonomie du conte, quel que soit son niveau d'intégration, ne signifie pas son indépendance: le contexte dans lequel le conte s'insère importe car il détermine en grande partie le sens et l'enrichit en le démultipliant, par un jeu de parallélismes, de correspondances et de contrastes.

71 Le contexte est le suivant. Le bœuf Sençeba et le roi lion sont liés par l'amitié. Le bœuf est devenu le conseiller intime du lion. C'est Dimna qui, par ses intrigues, a permis ce rapprochement alors qu'il visait le but opposé : il convoitait d'obtenir pour lui-même cette position sociale des plus enviables. Calila, dans son dialogue avec Dimna, lui fait prendre conscience qu'il est responsable de son propre malheur et lui conseille d'abandonner ses projets ambitieux. Mais ces conseils de prudence n'arrêtent pas l'audacieux Dimna. Tous ses efforts sont maintenant consacrés à l'élimination du bœuf. Il souhaite provoquer un affrontement entre les deux amis, mais un affrontement qui ne prenne pas la forme d'un combat dont il ne contrôlerait pas l'issue. Le conte des pluviers qu'il raconte à Sençeba a précisément pour but de dissuader le bœuf de s'exposer à un tel combat.

72 Ainsi, Dimna défend l'idée que l'on doit éviter de courir des risques inutiles, que le combat direct n'est à envisager qu'en dernier recours et qu'il ne faut pas sous-estimer la force de son ennemi. C'est là le sens de la thèse explicite formulée par le conte :

Non se deve ninguno meter a peligro podiendo estorçer, ca si muere, pierde su alma et peca, et si vençe, es ventura. Mas el omne de buen entendimiento pone la lid en fin de todas sus artes, et dizen : -Non despreçies al enemigo flaco et desonrado, et más si fuere artero, quanto más el león que es tan atrevido et tan fuerte comme tú sabes ; ca el que menospreçia fazienda de su enemigo et lo tiene en nada acaésçele lo que acaesçió al mayordomo de la mar con la ave que dezían tittuya.

On ne doit jamais s'exposer au danger lorsqu'on peut l'éviter car, si l'on meurt, on perd son âme et on pèche, et si l'on vainc, c'est par hasard. Au contraire, l'homme de bon jugement considère le combat comme le dernier de tous ses recours, et il est dit : « Ne sous-estime pas l'ennemi faible et sans prestige, surtout s'il est rusé », et à plus forte raison le lion qui est, comme tu le sais, très hardi et très fort ; car à qui sous-estime la capacité de son ennemi et fait peu de cas de lui, il advient ce qu'il advint à l'intendant de la mer avec l'oiseau que l'on nommait « tittuy "

73 Cette thèse est argumentée à partir d'une sentence (citée comme autorité et soumise à un raisonnement $a$ fortiori) et prouvée par le conte $(c a)$. Le conte apparait dès le départ comme un exemple a contrario: il montre ce qu'il ne faut pas faire, l'exemple à ne pas suivre. D'ailleurs, les dernières lignes tirent la conclusion de ce raisonnement : " non tengo que es consejo que lidies con el león...» («je te déconseille de te battre avec le lion »).

L'encadrement du conte par un appareil argumentatif de cette sorte est systématique dans le Calila, mais il convient de distinguer les formules de raccord, les formules de motivation de l'insertion et les formules sentencieuses, qui jouent des rôles différents.

Les formules de raccord permettent de sauvegarder la logique du dialogue. Elles opèrent des raccords dialogiques entre le conte enchâssé et le récit-cadre: « ¿Cómo fue eso?» («Comment cela?») au début du conte ou « Non te di este enxenplo sinon porque...» 
("si je t'ai donné cet exemple, c'est seulement parce que...») à la fin du conte sont les plus fréquentes. Elles sont à peu près immuables et relèvent d'un pur mécanisme conventionnel qui «signale » l'enchâssement, presque au même titre que nos guillemets modernes.

Les formules qui soulignent la motivation de l'insertion répondent, quant à elles, à une logique thématique. Presque toujours, cette motivation est une similitude ou une quasi identité. Le parallélisme syntaxique " acaésçele lo que acaesçió... » (« il lui advient ce qu'il advint... ») est on ne peut plus banal dans le Calila, notamment dans les exemples a contrario. D'ailleurs, il est strictement dupliqué ici, au moment de l'insertion du conte de la tortue et des deux canards: "acaesçerle ha lo que acaesçió al galápago " («il lui adviendra ce qu'il advint à la tortue »), indiquant un autre exemple a contrario.

Les formules sentencieuses, enfin, qu'elles soient affichées comme telles ou non, répondent à une logique argumentative. Elles énoncent la thèse à démontrer ou un argument qui donne plus de poids à cette thèse. Contrairement aux deux autres types de formules, elles sont relativement autonomes et leur place n'est pas immuable. Elles peuvent apparaitre avant le conte et après, et se dupliquent parfois en deux formulations différentes.

Dans notre texte, on retrouve ce schéma au deuxième niveau d'intégration, soit pour l'enchâssement du conte de la tortue et des deux canards dans le conte du pluvier.

Si on laisse momentanément de côté le conte de la tortue et des deux canards (le niveau narratif le plus profond ou troisième niveau) pour ne considérer que le deuxième niveau, le conte se résume à deux grandes séquences, elles-mêmes subdivisées en quatre sousséquences :

I. La perte des poussins : il faut savoir ce que l'on vaut

1. Le pluvier et la femelle débattent de l'emplacement de leur futur nid :

a) Le mâle, par commodité, opte pour rester au bord de la mer.

b) La femelle craint le danger que constitue la mer et préfèrerait pondre ses oeufs

ailleurs.

c) Le mâle pense que l'intendant de la mer n'osera pas lui faire du tort.

d) La femelle tente de le détromper en racontant le conte de la tortue et des deux canards.

2. Le pluvier, bien qu'il déclare comprendre le sens profond du conte (« Entendido he lo que dexiste »), reste inflexible et les poussins naissent au bord de la mer.

3. L'intendant de la mer fait monter les flots et s'empare des poussins.

4. La femelle tire la conclusion de cette catastrophe («non sabíamos lo que valíamos »).

II. La restitution des poussins : il faut savoir ce que vaut l'adversaire

1. Le mâle ne s'avoue pas vaincu et entame une plainte pour obtenir réparation:

d'abord auprès des autres pluviers, qui s'unissent à lui ;

2. puis, auprès des autres oiseaux, qui s'unissent à eux;

3. et, enfin, auprès du roi des oiseaux, le faucon doré, qui répond à l'appel de la communauté et écoute sa requête.

4. Avant même qu'une action ne soit engagée contre lui par le faucon, l'intendant de la mer, intimidé, restitue les poussins à leurs parents.

La structure narrative est donc globalement symétrique et se développe à partir du schéma perte / restauration. Comme dans l'exemple « Leo » du Sendebar, on a la sensation d'avoir à faire à deux contes réunis en un. La duplication est ici un trait caractéristique du récit. Cette duplication est, d'ailleurs, de deux sortes. Elle affecte la structure interne du récit, mais aussi la narration comme acte même de raconter (par le procédé de l'enchâssement), ce qui a, là encore, des conséquences directes sur l'interprétation 
morale qui lui est assignable. Cependant, comme nous allons tenter de le montrer, nous avons affaire ici à une démultiplication plutôt qu'à une duplication de l'interprétation ${ }^{28}$.

2. Lecture implicite initiale

81 Au premier abord, la moralité que propose Dimna à Sençeba semble claire et distincte, si ce n'est univoque. La portée argumentative d'un conte se fonde toujours sur une relation d'analogie qu'il est facile d'isoler pour le récepteur ${ }^{29}$. Dans ce cas précis, les analogies de situation semblent même soulignées par de nombreuses analogies d'expression ${ }^{30}$. Par la répétition de l'expression "a peligro ", le texte souligne implicitement que le pluvier s'expose au danger alors qu'il pourrait l'éviter (car c'est précisément ce qu'annonçait la formule sentencieuse initiale). Or, la prudente stratégie qui consiste à prévenir et éviter le danger est celle que préconise la femelle du pluvier. Ainsi s'ébauche un parallélisme entre le dialogue du récit-cadre, qui oppose Sençeba à Dimna, et celui du conte, qui oppose le pluvier à sa femelle. Dans ces deux dialogues, les personnages semblent jouer le même rôle. En outre, ce parallélisme devient une concomitance appuyée lorsque la femelle se met à relater un conte : comme Dimna, la femelle assume le rôle de narrateur désireux de montrer à son interlocuteur la catastrophe que peut entraîner un comportement inadéquat face à un ennemi que l'on sous-estime. Cet ennemi, qui est le lion dans le récit-cadre, est incarné par l'intendant de la mer dans le conte enchâssé : ces deux personnages sont donc eux-mêmes mis parallèle. Mieux, la motivation que la femelle assigne à son conte («El que non quiere creer a su amigo...», «Celui qui ne veut pas croire son ami... ») reprend, de façon complémentaire, celle que Dimna avait assignée au sien: à la méfiance insuffisante envers l'ennemi répond ici le manque de confiance envers l'ami. Les structures du récit-cadre et celles du récit enchâssé semblent donc se répondre terme à terme dans un parallélisme quasi transparent :

\begin{tabular}{|l|l|}
\hline & Lecture implicite initiale \\
\hline \hline Pluvier & Sençeba \\
\hline \hline Femelle du pluvier & Dimna \\
\hline \hline Intendant de la mer & Lion \\
\hline \hline Faucon doré & $\varnothing$ \\
\hline
\end{tabular}

82 La catastrophe qui clôt la première séquence (le vol des poussins par l'intendant de la mer) est logiquement la conséquence de l'attitude désinvolte du pluvier et correspond, dans le récit-cadre, à la défaite probable du bœuf contre le lion. Cette interprétation implicite - parce que seulement suggérée par des parallélismes de situation et d'expression - reste tout à fait cohérente lorsque l'on passe au troisième niveau de narration, soit au conte de la tortue et deux canards.

83 Tout d'abord, je voudrais faire quelques remarques sur la structure de ce conte. Elle peut être schématisée de la façon suivante :

- 1. Équilibre initial. Une tortue et deux canards, qui vivent près d'une source, sont amis.

- 2. Rupture de l'équilibre. La source vient à se tarir et les canards, ayant décidé de partir vers une autre source, veulent prendre congé de la tortue. 
- 3. Rétablissement d'un équilibre (par un pacte). Devant les protestations de la tortue, les canards imaginent le moyen de l'emmener avec eux, à condition qu'elle se garde de parler. La tortue mord le centre d'un bâton dont les canards saisissent les extrémités et tous trois s'envolent.

- 4. Rupture de l'équilibre (non respect du pacte). Voulant répondre aux paroles d'étonnement prononcées par des hommes, témoins du prodige, la tortue ouvre la bouche, tombe et meurt. la communauté qu'elle forme avec son mari et la suite du conte, d'ailleurs, confirmera cette dimension politique sous-jacente. Ce qui est le plus pertinent dans le parallélisme entre les deux récits, c'est l'idée de confiance trahie ou déplacée. Non seulement le pluvier n'a pas confiance en sa femelle, mais il a trop confiance en ses propres forces, il ne sait pas ce qu'il vaut face à l'intendant de la mer: "non sabíamos lo que valíamos" (« nous ne savions pas ce que nous valions »), lui dit la femelle après la catastrophe. La correspondance entre les personnages est donc tout à fait cohérente, selon une lecture initiale que nous nommerons «implicite» (car rien ne la pose explicitement dans le texte) : Sençeba correspond au pluvier qui, à son tour, est censé ressembler à la figure de la tortue ; Dimna correspond à la femelle qui, elle-même, joue un rôle analogue à celui des canards $^{31}$

\begin{tabular}{|l|l|}
\hline & Lecture implicite initiale \\
\hline \hline Tortue & Pluvier = Sençeba \\
\hline \hline Deux canards & Femelle du pluvier = Dimna \\
\hline
\end{tabular}

L'interprétation que j'ai détaillée est, me semble-t-il, celle que suggèrent, dans un premier temps, les nombreux parallélismes de situations et d'expressions entre le récitcadre et les contes enchâssés. Malgré cette cohérence, je voudrais montrer l'instabilité du système de l'exemplarité dans ce conte, en gageant qu'elle révèle une instabilité plus générale, peut-être fondamentale, de tout récit exemplaire. En effet, dans la seconde 
séquence du conte des pluviers, cette interprétation initiale ne s'impose plus aussi facilement. En effet, il existe alors trois obstacles à l'exploitation exemplaire du récit :

- a) Le pluvier gagne l'appui des autres oiseaux et de leur roi, le faucon doré, et obtient réparation du tort qu'il a subi : l'intendant de la mer restitue les poussins. Ce revirement de situation semble desservir le propos initial du conte : si le pluvier représente Sençeba, ce dernier, d'après ce que suggère le conte, semble donc avoir des chances de vaincre le lion. Le système de correspondances qui relie Sençeba à la figure du pluvier et le lion à celle de l'intendant de la mer peut apparaître très partiel au regard de l'extension du conte, puisqu'il néglige toute la dernière partie, consacrée à la récupération des poussins, comme si la portée exemplaire du récit était concentrée dans la première séquence. Les structures de la dernière séquence du conte ne semblent pas motivées du point de vue de l'exploitation argumentative, ou éthique, du récit. Ainsi, l'entreprise active du pluvier pour obtenir réparation du préjudice qu'il a subi semble coupée de la morale finale du conte.

- b) Si le pluvier finit par vaincre, les conseils de la femelle sont, eux aussi, démentis à la fin du conte. Est-ce à dire que Dimna, à travers le personnage de la femelle du pluvier qui est construit comme son double, mettrait en scène l'échec de sa propre parole?

- c) Plus fondamentalement encore, le personnage du faucon n'est apparemment le reflet d'aucun autre personnage de la trame principale. Serait-ce une entorse au principe d'économie de moyens qui semble lié au récit exemplaire?

La contradiction n'est pas totale et le conte garde une cohérence possible, si l'on admet que cette cohérence est nécessairement instable. Il se trouve, en effet, que le texte met en œuvre des moyens pour sauvegarder la viabilité de cette interprétation initiale. Trois d'entre eux peuvent être exposés :

- a) La perte des poussins reste l'enjeu du conte, même dans sa seconde séquence. Les formules qui sont adressées aux oiseaux pour leur demander de l'aide le rappellent à deux reprises :

ca bien podría acaesçer a vos lo que a mí acaesçió / aperçibiéronlas porque les acaesçería otro tal commo a él acaesçiera.

car ce qui m'est advenu pourrait bien vous advenir à vous aussi / ils les prévinrent qu'il pouvait leur advenir à eux ce qu'il lui était advenu à lui.

Ces expressions reprennent exactement les formules qui spécifient la motivation des contes enchâssés au moment de leur insertion. Ce qui est arrivé au pluvier peut donc arriver à tout un chacun, et notamment aux récepteurs du récit. Ainsi, ces expressions ressemblent fort à ce que l'on pourrait appeler des formules internes de motivation : de l'intérieur, à partir de sa propre matière narrative, le conte appelle l'exemplarité. Elles contribuent à ce que le malheur advenu au pluvier reste l'enjeu d'une exemplarité a contrario jusqu'à la fin du récit, même si l'issue du conte semble désavouer l'orientation de cette exemplarité. Par ailleurs, la sentence énoncée par Dimna avant de relater le conte permet, par sa formulation ambiguë, de garder une moralité à double tranchant :

el omne de buen entendimiento pone la lid en fin de todas sus artes

l'homme de bon jugement considère le combat comme le dernier de tous ses recours

Selon le contexte, dire que l'on considère le combat comme un dernier recours peut signifier qu'on tente de l'éviter ou, au contraire, que l'on se réserve bel et bien le droit d'en user. Les deux sens peuvent très bien convenir ici : le pluvier et ses compagnons envisagent la lutte comme une possibilité réelle mais, dans les faits, ils ne passent pas à 
l'acte contre l'intendant de la mer. Les oiseaux déclarent à leur roi qu'ils attaqueront leur ennemi s'il ne cède pas :

Et si lo fiziere, bien, et si non, aparejarnos hemos a lidiar con él.

E s'il le fait, fort bien ; sinon, nous nous préparerons à nous battre contre lui.

L'attitude des oiseaux ne contredit donc pas la moralité annoncée du conte.

- b) Quant au conseil de Dimna, tel qu'il se reflète dans le conseil donné par la femelle du pluvier, la contradiction, là non plus, n'est pas totale, si l'on considère la formulation de la moralité finale :

non tengo que es consejo que lidies con el león, nin que contiendas con él por ti mismo je te déconseille de te battre contre le lion ou de l'affronter par toi-même.

91 Le pluvier n'a pas attaqué l'intendant de la mer par lui-même, mais il a obtenu l'appui de ses amis, membres de la communauté des oiseaux et de son roi, le faucon. D’une certaine façon, s'il n'a pas observé le conseil de sa femelle à la lettre, il l'a appliqué dans l'esprit, ce qui ne remet pas en cause le lien qui unit les amis. Et précisément, le bœuf Sençeba, dans le récit-cadre, ne bénéficie pas de l'aide d'amis contre le lion : seul animal herbivore dans un monde de carnivores, il ne doit pas s'exposer au danger que représente le lion.

- c) Du même coup, on peut justifier in extremis l'absence dans le récit-cadre d'une figure qui pourrait correspondre au faucon, ce deus ex machina qui viendrait sauver Sençeba.

L'absence de correspondance ne dessert pas forcément l'exemplarité du conte : elle fait sentir au destinataire, en l'occurrence au bœuf Sençeba, qu'il est seul et démuni face à son adversaire.

\section{Lecture explicite}

Toute l'interprétation que nous avons détaillée jusqu'ici est produite par les structures du récit, mais elle est instable. J'ai conscience que, si elle est possible et justifiée au regard du texte, elle ne l'est que jusqu'à un certain point. En effet, un élément de poids vient la dénier. Il s'agit de la correspondance explicite que le narrateur du conte, Dimna, pose d'emblée au moment où il entreprend sa narration :

el que menospreçia fazienda de su enemigo et lo tiene en nada acaésçele lo que acaesçió al mayordomo de la mar con la ave que dezían tittuya

à qui sous-estime la capacité de son ennemi et fait peu de cas de lui, il advient ce qu'il advint à l'intendant de la mer avec l'oiseau que l'on nommait « tittuy »

Cette formule qui motive l'insertion du conte suggère une «lecture explicite » du conte, fondée sur le parallélisme suivant (du moins en ce qui concerne les personnages du pluvier et de l'intendant de la mer) :

\begin{tabular}{|l|l|l|}
\hline & I. Lecture implicite initiale & II. Lecture explicite \\
\hline \hline Pluvier & Sençeba & Lion \\
\hline \hline Femelle du pluvier & Dimna & $?$ \\
\hline \hline Intendant de la mer & Lion & Sençeba \\
\hline \hline Faucon doré & $\varnothing$ & Lion \\
\hline
\end{tabular}


est figure par l'intendant de la mer, il est bel et bien vaincu par son ennemi, le pluvier, à la fin de l'histoire, l'exploitation argumentative que fait Dimna dans le récitcadre apparaît fort cohérente : l'intendant de la mer a négligé la force de son ennemi (il l'a attaqué à tort, puisqu'en fin de compte, il a dû reculer devant lui) et, s'il attaque le lion, Sençeba risque de connaître le même sort. Cette lecture est renforcée par l'intervention, à la fin du récit, de la figure royale du faucon doré qui rappelle la figure royale du lion dans le récit-cadre. Dans ce cas, entre le début et la fin du conte, la correspondance entre les actants a imperceptiblement subi un glissement: si Sençeba correspond toujours à la figure de l'intendant de la mer, le lion, en revanche, se reflète maintenant davantage dans celle du faucon que dans celle du pluvier. Le lion s'incarne donc successivement dans la figure du pluvier et celle du faucon. Ce glissement ne nuit pas à la portée éthique du conte, bien au contraire. D'un point de vue narratif, le passage du pluvier au faucon se fait par une mise en scène de la communauté politique. Le récit s'appuie sur une conception de la société et en produit une image concrète. Le lien d'amour et de fraternité entre les individus d'une même espèce (les pluviers) et, au-delà, d'un même genre (les oiseaux) est le gage du droit et le principe qui permet à chaque individu d'en jouir. La communauté, cimentée par l'amour politique, néanmoins est impuissante par elle-même :

mas ¿qué es esto que podríamos fazer de daño a la mar e a su mayordomo?

mais comment donc pourrions-nous causer du tort à la mer et à son intendant?

Prenant progressivement confiance en ses propres possibilités ${ }^{32}$, cette communauté ne devient opérante que parce qu'elle en appelle, en dernier recours, à son roi. Ce dernier apparaît comme l'émanation de la communauté et, en même temps, le principe qui lui donne sa vigueur. C'est pourquoi il serait sans doute un peu erroné de réduire le sens de cette image à l'adage " l'union fait la force ». "L'union fait le roi, qui fait la force » serait ici plus juste : le pouvoir collectif s'incarne dans la figure du monarque. L'instance royale n'est pas logiquement séparée de la communauté, elle en est la plus haute expression. Ainsi, le conte passe des intérêts de l'individu à ceux du roi par un mouvement continu. Si le faucon est fort, c'est parce qu'il réunit la force de tous, mais, en même temps, sa force dépasse la somme de toutes les forces individuelles: là où la communauté seule est impuissante, parce qu'elle se réduit à une juxtaposition quantitative, le roi est puissant parce qu'il est une figure de la synthèse. Dans ce cas, il peut être vu aussi comme un symbole du passage de la force brute à la force fondée en droit. Cette métaphore politique n'a pas de relation directe avec la situation du récit-cadre, à moins de considérer que le texte, par cette union d'une même famille d'animaux - les oiseaux - contre l'intendant de la mer rappelle l'opposition entre la famille des carnivores (le lion et les chacals) et un herbivore individuel (le bœuf Sençeba). Avant tout, la métaphore offerte par le conte a l'avantage de bien cadrer avec sa moralité : l'intendant de la mer qui croyait s'opposer à un simple pluvier et lui faire du tort impunément, se retrouve en fait confronté à un ennemi puissant et royal, le faucon doré. Ce glissement sert à merveille - et presque terme à terme - la thèse que Dimna avait énoncée avant de relater le conte ${ }^{33}$.

Seule reste en suspens la figure de la femelle. Qui est ce personnage qui conseille le pluvier, c'est-à-dire le lion dans le récit-cadre ? Si le bœuf, comme récepteur du conte, ne saurait l'associer à aucun personnage de son entourage, le lecteur, quant à lui, peut faire 
le rapprochement avec Dimna lui-même qui, dans le récit-cadre, ne cesse de mettre en garde le roi contre le bœuf :

\begin{tabular}{|l|l|l|}
\hline & I. Lecture implicite initiale & II. Lecture explicite \\
\hline \hline Pluvier & Sençeba & Lion \\
\hline \hline Femelle du pluvier & Dimna & Dimna [ironie] \\
\hline \hline Intendant de la mer & Lion & Sençeba \\
\hline \hline Faucon doré & $\varnothing$ & Lion \\
\hline
\end{tabular}

Le procédé comporte une dimension ironique évidente. Bien souvent dans le Calila, le fourbe qui utilise le conte pour tromper son adversaire lui donne en même temps tous les éléments qui lui permettraient de se détromper. Le conte est le moyen de la tromperie, mais aussi son expression. Il dissimule et, en même temps, révèle les intentions du narrateur. Ici, Dimna, à mots couverts, révèle au bœuf qu'il travaille à sa perte auprès du lion.

Si l'on passe au troisième niveau de la narration (conte de la tortue), la cohérence devient problématique, mais reste possible. La tortue et sa chute peuvent toujours représenter Sençeba et sa mort à venir mais, au prix d'une rupture dans le système de correspondances : le troisième niveau narratif se rapporte alors directement au premier niveau, en faisant abstraction du niveau intermédiaire (c'est ce que j'ai figuré par le signe $« \emptyset »)$ :

\begin{tabular}{|l|l|l|}
\hline & I. Lecture implicite initiale & II. Lecture explicite \\
\hline \hline Tortue & Pluvier = Sençeba & $\varnothing=$ Sençeba [ironie] \\
\hline \hline Deux canards & Femelle du pluvier = Dimna & $\varnothing=$ Dimna+ lion [ironie] \\
\hline
\end{tabular}

Face à la tortue qui trouve la mort, les deux canards peuvent représenter le couple Dimna-lion, deux carnivores qui s'opposent à l'herbivore Sençeba : l'herbivore qui a voulu se joindre à la communauté des carnivores connaît le sort de la tortue, animal pesant lié à la terre, qui a voulu s'élever dans les airs avec les oiseaux. Dans le récit-cadre, le bœuf est bien le tiers exclu au terme d'une lutte d'influences sous couvert d'amitié. Bien que le motif de la lutte soit absent du conte de la tortue et des deux canards, le récit met lui aussi en scène une amitié rompue et en attribue, en outre, la responsabilité à la victime elle-même, incapable de s'adapter à la situation. Le conte annonce donc ironiquement au bœuf le sort fatal qui l'attend contre le lion et le chacal. Quand il prendra conscience de sa chute, il ne pourra s'en prendre qu'à lui-même. La cible de l'ironie est le destinataire du conte parce que le narrateur en sait plus que lui et parce que le lecteur partage ce savoir. 
Au total, il s'agit d'un système interprétatif cohérent, mais qui reste instable, parce que le lion est incarné dans deux figures, mais aussi parce que ce système rompt la continuité des correspondances d'un niveau narratif à l'autre.

4. Lecture implicite finale

103 Pour rétablir un équilibre, en remédiant à ces deux facteurs d'instabilité, il est possible d'attribuer respectivement les rôles du pluvier et du faucon au roi et au chacal, ce qui n'est pas arbitraire: la relation de monarque à sujet existe dans chaque récit. Il s'agit alors d'une «interprétation implicite finale ${ }^{34}$. Dimna, quant à lui, présente de nombreuses similarités avec le pluvier du conte qu'il relate. Comme lui, il a perdu un bien très précieux (la faveur dont il jouissait auprès du lion) et il attribue cette perte au bœuf comme le pluvier l'attribue à l'intendant de la mer. Par le conte du pluvier, au lieu d'exposer au bœuf des situations où il puisse se reconnaître, Dimna raconte donc sa propre histoire. De fait, dans le conte du pluvier comme dans le récit-cadre, le personnage lésé parvient à mettre le monarque de son côté pour vaincre son ennemi. De plus, en toute logique, le couple que le pluvier forme avec sa femelle est une figure exacte du couple des deux chacals, Dimna et Calila. On a alors un système de correspondances parfait qui associe membre à membre les personnages du récit-cadre et du conte :

\begin{tabular}{|l|l|l|l|l|}
\hline & $\begin{array}{l}\text { I. Lecture implicite } \\
\text { initiale }\end{array}$ & $\begin{array}{l}\text { II. } \\
\text { explicite }\end{array}$ & $\begin{array}{l}\text { Lectur. Lecture implicite } \\
\text { finale }\end{array}$ \\
\hline \hline Pluvier & Sençeba & Lion & Dimna [ironie] \\
\hline \hline Femelle du pluvier & Dimna & Dimna [ironie] & Calila [ironie] \\
\hline \hline $\begin{array}{l}\text { Intendant de la } \\
\text { mer }\end{array}$ & Lion & Sençeba & Sençeba \\
\hline \hline Faucon doré & $\varnothing$ & Lion & Lion \\
\hline
\end{tabular}

Le parallélisme entre Calila et la femelle du pluvier est très cohérent. Avant que Dimna ne connaisse la disgrâce, Calila, dans le récit-cadre, ne cesse de lui conseiller de renoncer à ses projets et de fuir le danger que représente le bœuf. Mais Dimna, comme le pluvier, passe outre. Dans le conte enchâssé, la défaite de l'intendant de la mer contre les oiseaux annonce donc clairement le revirement de situation que Dimna prépare depuis déjà longtemps : la défaite du bœuf qu'il veut supplanter. On voit donc, selon cette nouvelle lecture implicite, que l'ironie envahit tout le récit. Dimna énonce à mots couverts au bœuf une vérité qu'il doit pourtant continuer d'ignorer, selon un paradoxe fréquent dans l'œuvre, un paradoxe qui montre que l'interprétation de l'histoire -comme l'interprétation de n'importe quels signes - n'est accessible que si l'on prend en compte un contexte. La touche ironique ne peut être appréciée que par le regard englobant de qui connaît déjà les machinations que Dimna a exposées à Calila. Le lecteur, qui en sait plus que le personnage du bœuf, est donc sollicité, en vertu de cette connaissance supplémentaire qu'il a du contexte.

Que penser alors du conte de troisième niveau, «la tortue et les deux canards »? Si le conte des pluviers a pu passer du statut d'exemplum a contrario à celui de récit ironique où 
le narrateur annonce la chute inéluctable du narrataire, le conte de la tortue ne pourraitil pas lui aussi fonctionner ainsi? En d'autres termes, en vertu de la correspondance établie au deuxième niveau de narration, qui associe Dimna au pluvier et Calila à la femelle du pluvier, lorsqu'on passe au troisième niveau, il s'établit naturellement, et sans rupture, le parallélisme suivant :

\begin{tabular}{|l|l|l|l|l|}
\hline & $\begin{array}{l}\text { I. Lecture implicite } \\
\text { initiale }\end{array}$ & II. Lecture explicite & III. Lecture implicite finale \\
\hline \hline Tortue & Pluvier = Sençeba & $\varnothing=$ Sençeba [ironie 1] & Pluvier = Dimna [ironie 2] \\
\hline \hline $\begin{array}{l}\text { Deux } \\
\text { canards }\end{array}$ & $\begin{array}{l}\text { Femelle du pluvier } \\
\text { Dimna }\end{array}$ & $\begin{array}{lll}\varnothing=\text { Dimna+ lion } \\
\text { [ironie 1] }\end{array}$ & $\begin{array}{l}\text { Femelle du pluvier = Calila } \\
{\left[\begin{array}{l}\text { ironie 2] } \\
\text { ou } \emptyset=\text { Sençeba + lion } \\
{[\text { ironie 2] }}\end{array}\right.}\end{array}$ \\
\hline
\end{tabular}

Si l'on admet que Dimna est représenté par le pluvier et que Calila correspond à sa femelle, le récit de la tortue et des deux canards prend alors tout son sens. La chute de la tortue préfigure donc la chute de Dimna, qui advient, de fait, au chapitre IV de l'œuvre, comme l'a voulu Ibn al-Muqaffa pour le texte arabe. Parce qu'il n'a pas écouté le conseil de son ami Calila, Dimna a causé sa propre perte. Les circonstances de la chute de la tortue deviennent alors pertinentes et ce, pour la première fois : la tortue meurt par la parole de même que Dimna, l'intrigant, le sophiste retors, est condamné pour en avoir fait usage. La logique de l'ironie est capable, elle aussi, de s'étager en degrés et en niveaux : on pourra parler, dans ce cas, d'« une ironie de niveau 2 » ou à la seconde puissance, une ironie contre celui qui ironise, par retournement contre son utilisateur. Dans le même ordre d'idée, une autre interprétation ironique de niveau 2 consisterait à voir dans le couple des canards, liés par l'amitié, le couple d'amis que sont le lion et le bœuf jusqu'à ce que Dimna ne les sépare. À vouloir s'introduire entre les amis, comme la tortue entre les deux canards, et à vouloir par là même occuper un lieu qui ne lui est pas destiné, Dimna connaît lui aussi la chute et le trépas ${ }^{35}$. Le tiers exclu, que nous avons envisagé il y a un instant comme une figure assignable au personnage du bœuf, est aussi, et surtout, le vrai visage du chacal Dimna.

Pour généraliser, l'ironie de niveau 1 a pour caractéristique de prendre pour cible le destinataire du conte, qui ne peut la repérer par ignorance d'un contexte. L'ironie de niveau 2, quant à elle, s'ajoute à la première en s'appliquant au narrateur lui-même. Seule une instance supérieure qui connaît l'ensemble du contexte, en l'occurrence le lecteur une fois qu'il a lu les chapitres III et IV, peut en saisir toutes les nuances. On remarquera ici que plus le niveau narratif est profond, plus la mise en abyme du récit est concentrée : ici le conte du niveau le plus profond (« La tortue et les deux canards ", conte troisième niveau), d'ailleurs fort bref, offre en miroir une synthèse saisissante de tout le récit-cadre, soit des chapitres III et IV de l'œuvre.

Conclusion

108 J'ai suggéré qu'il existe une instabilité fondamentale de l'exemplarité des récits dans le Sendebar et le Calila e Dimna. L'hypothèse, pour être confirmée, devrait être confrontée à d'autres contes de ces recueils. Mes conclusions seront pour l'instant limitées. Le récit 
dans le récit s'énonce de manière claire et distincte en lui-même, mais construit un système complexe, voire indécidable, quand il s'agit d'attribuer des rôles éthiques aux différents personnages en regard du récit-cadre. L'exemplarité ne dépend donc pas seulement de l'hésitation entre un récit et sa morale explicite, mais surtout de la jointure, plus ou moins contraignante mais jamais totalement rigide, entre deux récits. Ce qui fonde l'exemplarité est peut-être ce jeu, au sens d'espace vide qui permet l'articulation de deux pièces et leur mouvement. Si la portée éthique du récit est elle-même instable, cette instabilité n'est pas une contradiction ou un brouillage du sens, mais plutôt une stratification en niveaux de la portée éthique, de la même façon qu'il existe des niveaux narratifs. Si un niveau d'interprétation éthique du récit est nécessairement celui qui s'énonce explicitement par la bouche du personnage-narrateur, d'autres niveaux d'interprétation, plus ou moins implicites, affleurent par endroits. Cette stratification n'exige pas une multiplicité d'énoncés pour amplifier la portée éthique du récit: une seule sentence ou un petit nombre de sentences peut concentrer une multiplicité de lectures possibles. Plutôt que de suggérer d'autres moralités pour le conte enchâssé, les multiples correspondances entre le conte et son récit-cadre sont autant de façons que le conte a de se rapporter à sa moralité unique. L'instabilité de l'exemplarité ne signifie donc pas que la portée morale du récit soit invérifiable, mais, qu'au contraire, le fonctionnement du récit la vérifie de plusieurs façons concomitantes. Si elle la morale est « introuvable », c'est parce qu'elle est partout, et qu'elle investit non seulement les structures des récits, mais aussi et surtout les interstices qui permettent leur confrontation. L'idée que la dimension éthique surgit lorsque le récit est en fonctionnement - et non lorsqu'il est achevé et réduit artificiellement à une moralité tend à confondre l'acte de lecture et l'interprétation morale. La dimension éthique des récits n'est peut-être rien d'autre que l'espace où ils s'énoncent.

\section{ANNEXES}

Les deux contes étudiés (et une traduction)Sendebar, « Leo » (éd. M.J. Lacarra, Madrid: Cátedra, 1989, p. 76-81).

Este privado primero fuese para el Rey e fincó los inojos ante él, e dixo :-Señor, non deve fazer ninguna cosa el omne fasta que sea çierto d'ella, e si lo ante fizieres, errallo as mal e dezirte he un enxenplo de un rey e de una su muger.

E el Rey dixo :-Pues, di agora e oírtelo he.

El privado dixo : -Oí dezir que un rey que amava mucho las mugeres e non avía otra mala manera sinon esta. E seié el Rey un día ençima de un soberado muy alto e miró ayuso e vido una muger muy fermosa e pagóse mucho d'ella. E enbió a demandar su amor e ella dixo que non lo podría fazer seyendo su marido en la villa. E quando el Rey oyó esto, enbió a su marido a una hueste. E la muger era muy casta e muy buena e muy entendida e dixo : -Señor, tú eres mi señor e yo só tu sierva e lo que tú quesieres, quiérolo yo, mas irme he a los vaños afeitar.

E quando tornó, diol' un libro de su marido en que avía leyes e juizios de los reyes, de 
cómmo escarmentavan a las mugeres que fazían adulterio. E dixo :-Señor, ley por ese libro fasta que me afeite.

E el Rey abrió el libro e falló en el primer capítulo cómmo devía el adulterio ser defendido, e ovo gran vergüença e pesól' mucho de lo qu'él quisiera fazer. E puso el libro en tierra e sallóse por la puerta de la cámara, e dexó los arcorcoles so el lecho en que estava asentado. E en esto llegó su marido de la hueste, e quando se asentó él en su casa, sospechó que ý durmiera el Rey con su muger, e ovo miedo e non osó dezir nada por miedo del Rey e non osó entrar do ella estava, e duró esto gran sazón. E la muger díxolo a sus parientes que su marido que la avía dexado e non sabía por quál razón. E ellos dixiéronlo a su marido : ¿ ¿Por qué non te llegas a tu muger?

E él dixo :-Yo fallé los alcorcoles del Rey en mi casa e he miedo, e por eso non me oso llegar a ella.

E ellos dixieron :-Vayamos al Rey e agora démosle enxenplo de aqueste fecho de la muger, e non le declaremos el fecho de la muger e, si él entendido fuere, luego lo entenderá.

E estonçes entraron al Rey e dixiéronle :-Señor, nós aviemos una tierra e diémosla a este omne bueno a labrar, que la labrase e la desfrutase del fruto d'ella. E él fízolo así una gran sazón e dexóla una gran pieça por labrar.

E el Rey dixo : $¿$ Qué dizes tú a esto?

E el omne bueno respondió e dixo :-Verdat dizen, que me dieron una tierra así commo ellos dizen e quando fui un día por la tierra, fallé rastro del león e ove miedo que me conbrié. Por ende dexé la tierra por labrar.

E dixo el Rey :-Verdat es que entró el león en ella, mas no te fizo cosa que non te oviese de fazer nin te tornó mal dello. Por ende, toma tu tierra y lábrala.

E el omne bueno tornó a su muger e preguntóle por qué fecho fuera aquello. E ella contógelo todo e díxole la verdat commo le conteçiera con él, e él creyóla por las señales quel' dixiera el Rey e después se fiava en ella más que non d'ante.

Ce premier conseiller alla trouver le roi, se mit à genoux devant lui et dit :-Seigneur, l'homme ne doit rien faire avant d'être sûr de son fait et, si tu agis avant, tu te fourvoieras. Je vais te dire l'exemple d'un roi et d'une de ses femmes.

Le Roi dit : -Dis-le donc et je l'entendrai.

Le conseiller dit :-J'ai entendu dire qu'un roi aimait beaucoup les femmes et qu'il n'avait pas d'autres mauvaises habitudes que celle-là. Le Roi se trouvait un jour sur une terrasse très élevée. Regardant en bas, il vit une femme très belle qui lui plut beaucoup. Il envoya quelqu'un demander son amour et elle répondit qu'elle ne pourrait accepter alors que son mari était dans la ville. Quand le roi entendit cela, il envoya son mari dans une armée. La femme était très chaste, très bonne et très intelligente. Elle dit :-Seigneur, tu es mon seigneur et je suis ta servante. Tout ce que tu veux, je le veux aussi. Mais je vais aller aux bains m'apprêter.

Quand elle revint, elle lui donna un livre qui était à son mari où il y avait des lois et des jugements des rois par lesquels ils châtiaient les femmes qui commettaient l'adultère. Et elle dit : -Lis ce livre jusqu'à ce que je sois apprêtée.

Le roi ouvrit le livre et trouva, au premier chapitre, que l'adultère devait être interdit. Il eut grand honte et se repentit fort de ce qu'il avait voulu faire. Il posa le livre par terre, sortit par la porte de la chambre et oublia ses pantoufles sous le lit où il était installé. Et, sur ce, le mari revint de l'armée et, quand il s'installa dans sa maison, il soupçonna que le Roi y avait dormi avec sa femme. Il eut peur, n'osa rien dire par crainte du Roi et n'osa 
entrer là où elle était, ce qui dura longtemps. Et la femme le dit a ses parents : elle dit que son mari l'avait délaissée et qu'elle ne savait pas pour quelle raison. Et ceux-ci dirent à son mari : -Pourquoi ne t'approches-tu point de ta femme?

Il dit :-J'ai trouvé les pantoufles du Roi dans ma maison et j'ai peur. C'est pour cela que je n'ose m'approcher d'elle.

Et ils dirent : -Allons trouver le Roi et faisons-lui un exemple de cette histoire de la femme sans lui révéler l'histoire de la femme. S'il est intelligent, il le comprendra aussitôt. Alors, ils entrèrent chez le Roi et lui dirent : -Seigneur, nous avions une terre et nous l'avons donnée à labourer à cet homme respectable, pour qu'il la laboure et en ait l'usufruit. C'est ce qu'il a fait une longue période durant, puis il l'a laissée en friches, ce qui dure depuis longtemps.

Le roi dit : -Que réponds-tu à cela?

Le bonhomme dit en réponse : -Ils disent vrai : ils m’ont donné une terre, comme ils le disent. Mais quand je suis allé un jour sur la terre, j'ai trouvé une trace du lion et j'ai eu peur qu'il ne me mange. C'est pourquoi j'ai laissé la terre en friches.

Le roi dit :-Il est vrai que le lion est entré sur ta terre, mais il n'a rien fait qu'il ne doive point te faire et tu n'en as reçu aucun préjudice. Donc, prends ta terre et laboure-la. Et le bonhomme revint auprès de sa femme et lui demanda comment toute l'histoire s'était passée. Elle lui raconta tout et lui dit la vérité de ce qu'il lui était advenu avec le Roi. Il la crut en raison des détails que lui avait donnés le Roi et, par la suite, il eut davantage confiance en elle qu'auparavant.

Calila e Dimna, chapitre III (éd. M.J. Lacarra et J.M. Cacho Blecua, Madrid : Castalia, 1984, p. 163-167).

Dixo Digna : -Non se deve ninguno meter a peligro podiendo estorçer, ca si muere, pierde su alma et peca, et si vençe, es ventura. Mas el omne de buen entendimiento pone la lid en fin de todas sus artes, et dizen : -Non despreçies al enemigo flaco et desonrado, et más si fuere artero, quanto más el león que es tan atrevido et tan fuerte comme tú sabes; ca el que menospreçia fazienda de su enemigo et lo tiene en nada acaésçele lo que acaesçió al mayordomo de la mar con la ave que dezían tittuya.

Dixo Sençeba : ¿¿Cómmo fue eso?

[Los tittuy y el mayordomo del mar]

Dixo Digna :-Dizen que una ave de las aves de la mar que dezían tittuya estava él et su fenbra en una ribera de la mar ; et quando vino el tiempo del poner de sus huevos, fízolo saber la fenbra al maslo, et díxole :-Busca un lugar apartado en que pongamos nuestros huevos.

Díxole el maslo : -Ponlos aquí en este nuestro lugar, ca el agua et la yerva son çerca de nos et esnos mejor que otro.

Díxole ella : -Piensa en lo que dizes, ca a peligro estamos en este lugar ; ca si se la mar tendiere en este lugar, levarnos ha nuestros pollos.

Dixo el maslo : -Non cuido que se tienda la mar sobre nos, ca sé que se teme el mayordomo de la mar que gelo vedaríamos.

Díxole la fenbra : -¡Cómmo eres loco en esto! Non as vergüença nin conosçes el bien en amenazar aquel con quien non puedes, ca dizen que non es ninguna cosa que mayor daño faga a ninguno que el omne. Oye lo que te digo, et fazlo. 
Et él non se quiso otorgar en aquello a que lo ella conbidava. Quando ella vido que la non quiso creer, dixo :-El que non quiere creer a su amigo, quando lo desengaña, acaesçerle ha lo que acaesçió al galápago.

Dixo el maslo : ¿¿Cómmo fue eso?

[Los dos ánades y el galápago]

Dixo ella : -Dizen que en una fuente avía dos ánades et un galápago, et eran amigos por la vezindat que era entre ellos. Desí vino el tienpo que les menguó el agua, et secóse la fuente. Quando esto vieron las ánades, acordaron de mudarse de aquella fuente a otra do avía mucha agua et a do serían viçiosas. Et vinieron para el galápago, et despidiéronse dél et dixiéronle :-Querémosnos ir deste lugar porque nos falleçió el agua.

Dixo el galápago : -A vos non falleçió el agua, que podedes ir donde quisiéredes. Mas a mí, mezquino, falleçió, que non puedo ir conbusco nin puedo guareçer sin agua. Ende vos ruego que catedes algunt consejo cómmo me podades levar conbusco.

Dixeron ellas : -Nós non lo podemos fazer, si non nos fizieses tal convenençia que, quando te leváremos et te viere alguno et fablare, que non le respondas.

Dixo él : -Así lo faré. Pues, ¿en quál guisa podría ser que me levásedes?

Dixieron ellas :-Morderás tú en medio de una fuste et travarémosnos de los cabos dél, et levarte hemos así.

Plogo desto al galápago, et leváronlo bolando por el aire ; et viéronlo los omnes, et maravilláronse et dixieron :-Ved qué maravilla : un galápago entre dos ánades que lo lievan en el aire.

Quando el galápago esto oyó, dixo : ¡Qué vos pese!

Et abriendo la boca para fablar, cayó en tierra et murió.

Dixo el tituy a la fenbra :-Entendido he lo que dexiste, mas non temas de la mar nin le ayas pavor.

Et ella puso sus huevos et sacó sus pollos. Quando lo vio el mayordomo de la mar, quiso saber quánto se podría guardar dél el tituy o qué arte faría, et diole lugar fasta que se finchó la mar et levó los pollos et su nido. Quando vino la fenbra a requerirlos et non los falló, dixo al marido : -Bien sabía yo al comienço deste nuestro fecho que esto acaesçería, et que se nos tornaría en nada a mí et a ti, que non sabíamos lo que valíamos. Cata quánto daño nos vino por esto.

Dixo el maslo : -Tú verás lo que faré, et en qué ençimaré mi fazienda.

Et fuese para sus amigos et querellóse desto, et díxoles : -Vós sodes mis hermanos et mis amigos para demandar el tuerto que yo resçebí. Pues ayudadme et guisad cómmo aya derecho, ca bien podría acaesçer a vos lo que a mí acaesçió.

Dixeron ellas :-Si así es commo tú dizes, derecho es que resçibamos tu ruego, mas ¿qué es esto que podríamos fazer de daño a la mar et a su mayordomo?

Dixo : -Ayuntémosnos et vayámosnos a las otras aves, et digámosgelo.

Et toviéronlo por bien, et fuéronse a las otras aves et dixéronles lo que acaesçiera, et aperçibiéronlas porque les acaesçería otro tal commo a él acaesçiera.

Dixéronles : -Así es commo vós dezides, mas ¿qué mal podemos fazer a la mar et a su mayordomo?

Dixéronles :-El rey de todas nos las aves es el falcón oriol. Llamémoslo fasta que se nos muestre.

Et fiziéronlo así, et mostróseles et díxoles : -¿Qué cosa vos ayuntó o por qué me llamastes? Dixéronle ellas lo que les acaesçiera por la mar et por su mayordomo. 
Dixéronle :-Tú eres nuestro señor et nuestro rey, et el poder que tú has creemos que es más fuerte que el mayordomo de la mar. Pues vete para él et ruégale que nos emiende el tuerto que nos fizo. Et si lo fiziere, bien, et si non, aparejarnos hemos a lidiar con él. Quando lo sopo el mayordomo de la mar, entendió su flaqueza apos la fortaleza del falcón oriol et tornó los pollos del tituy.

Et yo non te di este enxenplo sinon porque non tengo que es consejo que lidies con el león, nin que contiendas con él por ti mismo.

Digna dit : -On ne doit jamais s'exposer au danger lorsqu'on peut l'éviter car, si l'on meurt, on perd son âme et on pèche, et si l'on vainc, c'est par hasard. Au contraire, l'homme de bon jugement considère le combat comme le dernier de tous ses recours, et il est dit : « Ne sous-estime pas l'ennemi faible et sans prestige, surtout s'il est rusé », et à plus forte raison le lion qui est, comme tu le sais, très hardi et très fort ; car à qui sousestime la capacité de son ennemi et fait peu de cas de lui, il advient ce qu'il advint à l'intendant de la mer avec l'oiseau que l'on nommait « tittuy » [pluvier]. Sençeba dit : -Comment cela?

[Les « tittuy » et l'intendant de la mer]

Digna dit : -On raconte qu'un oiseau parmi les oiseaux de la mer, que l'on nommait « tittuya », était avec sa femelle au bord de la mer. Quand vint le temps de la ponte, la femelle le fit savoir au mâle et lui dit :-Cherche un lieu à l'écart où je puisse pondre nos oeufs.

Le mâle dit : -Ponds-les ici-même, dans ce lieu où nous sommes, car l'eau et l'herbe sont tout proches, ce qui en fait un meilleur endroit que d'autres.

Elle dit :-Pense bien à ce que tu dis, car nous sommes en danger dans ce lieu ; car si la mer avançait jusqu'à ce lieu, elle emporterait nos poussins.

Le mâle dit :-Je ne pense pas que la mer s'avance jusqu'à nous, car je sais que l'intendant de la mer craindrait que nous l'en empêchions.

La femelle lui dit :-Comme tu es fou de penser cela! Tu n'as point de honte et méconnais le bien quand tu menaces celui sur qui tu n'as aucun pouvoir, car il est dit que rien n'est plus nuisible à autrui et à soi-même que l'homme. Écoute ce que je te dis et fais-le.

Mais il refusa d'acquiescer à ce qu'elle le priait de faire. Quand elle vit qu'il ne voulait pas la croire, elle dit :-À qui ne veut pas croire son ami quand il le détrompe, il adviendra ce qu'il advint à la tortue.

Le mâle dit : -Comment cela?

[Les deux canards et la tortue]

Elle dit : -On raconte que dans une source il y avait deux canards et une tortue qui étaient amis en raison de leur voisinage. Cependant, vint un temps où leur eau s'amenuisa et la source se tarit. Quand les canards virent cela, ils décidèrent d'abandonner cette source pour une autre où il y avait beaucoup d'eau et où ils vivraient dans l'aisance. Ils vinrent trouver la tortue pour prendre congé d'elle et lui dirent :-Nous voulons quitter ce lieu parce que notre eau s'est épuisée.

La tortue dit :-Pour vous l'eau n'est pas épuisée, puisque vous pouvez aller où bon vous semble. Mais c'est pour moi, malheureuse, qu'elle est épuisée, puisque je ne puis partir avec vous ni survivre sans eau. C'est pourquoi je vous prie d'envisager quelque expédient pour que vous puissiez m'emmener avec vous. 
Ils dirent : -Nous ne pouvons le faire à moins que tu ne prennes auprès de nous l'engagement, si nous t'emmenons et si quelqu'un vient à te parler en te voyant, de ne point lui répondre.

Elle dit : -Je m'y engage. Et maintenant, comment sera-t-il possible que vous m'emmeniez?

Ils dirent : -Tu mordras le centre d'un bâton dont nous saisirons les deux bouts et nous t'emmènerons ainsi.

Cela plut à la tortue et ils s'envolèrent en l'emportant dans les airs. Des hommes les virent et, émerveillés, ils dirent :-Regardez ce prodige : une tortue entre deux canards qui l'emportent dans les airs.

Quand la tortue entendit cela, elle dit :-Grand mal vous fasse!

Et, ayant ouvert la bouche pour parler, elle tomba à terre et mourut.

Le « tituy » dit à sa femelle : -J'ai compris ce que tu as dit, mais ne crains pas la mer et ne t'en effraie point.

Elle pondit ses oeufs et fit naître ses poussins. Quand l'intendant de la mer vit tout cela, il voulut savoir jusqu'à quel point le « tituy » pourrait s'opposer à lui et quelle ruse il emploierait pour cela. Il le laissa faire mais, ensuite, la mer s'accrut et emporta les poussins avec leur nid. Quand la femelle vint les chercher et ne les trouva point, elle dit à son mari : -Je savais bien dès le début de cette histoire que cela adviendrait et qu'elle tounerait mal, pour toi comme pour moi, car nous ne savions pas ce que nous valions. Vois le mal qui nous est arrivé à cause de cela.

Le mâle dit : -Tu verras ce que je vais faire et comment je mènerai mon affaire à bon terme.

Et il s'en alla trouver ses amis pour se plaindre auprès d'eux et leur dit :-Vous êtes mes frères et mes amis, qui devez demander raison du tort que j'ai reçu. Aidez-moi donc et faites en sorte que j'obtienne justice, car ce qui m'est advenu pourrait bien vous advenir à vous aussi.

Ils dirent : -Si tout est comme tu le dis, il est juste que nous recevions ta requête, mais comment donc pourrions-nous causer du tort à la mer et à son intendant ?

Il dit : -Unissons-nous et allons trouver les autres oiseaux et parlons-leur de cela.

Ils approuvèrent allèrent trouver les autres oiseaux, leur dirent ce qu'il était advenu et les prévinrent qu'il pouvait leur advenir à eux ce qu'il lui était advenu à lui.

Ils leur dirent : - La situation est comme tu le dis, mais quel mal pouvons-nous faire à la mer et à son intendant?

Ils leur répondirent : -Notre roi à nous tous, les oiseaux, est le faucon doré. Appelons-le jusqu'à ce qu'il se présente.

Ainsi fut fait. Il se présenta et leur dit : -Qu'est-ce qui vous a poussé à vous unir et pourquoi m'appelez-vous?

Ils lui dirent ce qui était advenu à cause de la mer et de son intendant.

Ils lui dirent : -Tu es notre seigneur et notre roi, et le pouvoir que tu as, nous croyons qu'il est plus fort que l'intendant de la mer. Va donc le trouver et demande-lui qu'il répare le tort qu'il nous a fait. Et s'il le fait, fort bien ; sinon, nous nous préparerons à nous battre contre lui.

Quand l'intendant de la mer sut tout cela, il comprit quelle était sa faiblesse au regard de la force du faucon doré et il rendit les poussins du « tituy ».

Et moi, si je t'ai donné cet exemple, c'est seulement parce que je te déconseille de te battre contre le lion ou de l'affronter par toi-même. 


\section{NOTES}

1. Les éditions retenues pour cette étude sont Calila e Dimna, éd. J.M. Cacho Blecua et M.J. Lacarra, Madrid : Castalia, 1993, et Sendebar, éd. M.J. Lacarra, Madrid : Cátedra, 1989. Toutes les citations des œuvres en sont tirées.

2. Anne-Marie Capdeboscq, « Calila e Dimna ou la morale introuvable », Les langues néolatines, 295 (1995), p. 155-176.

3. Nous évoquerons ce cas plus en détails dans notre présentation des textes.

4. Je ne fais ici que rappeler des éléments déjà synthétisés par María Jesús Lacarra, Cuentística medieval en España : los orígenes, Zaragoza : Universidad de Zaragoza, 1979, notamment p. 11-31.

5. Ibn al-Muqaffa' fut un grand lettré qui occupa la charge de secrétaire auprès de plusieurs hauts dignitaires de son temps. Voir, par exemple, l'introduction de Pierre Miquel à sa traduction française de la version arabe (Le livre de Kalila et Dimna, Paris : Klincksieck, 1980, p. IX-XI).

6. Voir Marta Haro Cortés, « El viaje sapiencial en la prosa didáctica castellana de la Edad Media ", in Actas del I Congreso Anglo-hispano, ed. A. Deyermond y R. Penny, Madrid : Castalia, vol. 2, 1994, p. 59-72, ainsi que Madeleine Pardo, «L'itinéraire spirituel de Berzebuey ", in Aux origines du contes en Espagne. Calila e Dimna, Sendebar, coord. B. Darbord, Crisol, 21 (1996), p. 89-101.

7. Pour plus de détails, voir M.J. Lacarra, Cuentística..., p. 16-17.

8. Pour mieux saisir le poids de ces circonstances, voir Michel Garcia, « Le contexte historique de la traduction du Sendebar et du Calila », in Aux origines du conte..., p. 103-113. 9. Voir B. Darbord, « Le roman des sept sages : étude d'une tradition en Espagne », in Aux origines $d u$ conte..., p. 25-60.

10. J'emprunte cette remarque à Federico Bravo, «El tríptico del diablo. En torno al libro del Sendebar », Bulletin Hispanique, 99-2 (1997), p. 347-371 (p. 366).

11. Cuentística..., p. 51.

12. Voir Bernard Darbord, «Le roman des sept sages... », p. 32 et 37.

13. Dans la pièce liminaire consacrée au voyage sapientiel de Berzebuey, les noms de ces personnages sont indiqués : le roi se nomme Diçelem et son conseiller, Burduben, mais les noms ne sont jamais repris dans le texte par la suite.

14. Cuentística..., p. 60-62.

15. Le texte castillan exploite à maintes reprises un jeu de mots qui campe le personnage de Dimna dans son rôle d'intrigant : Dimna - appelé également « Digna » - a perdu sa « dignidat » (sa « dignité », au sens de prestige social) et tente de la recouvrer.

16. Dans le chapitre IV, le fait que Dimna soit publiquement accusé de traitrise, condamné à mort et exécuté semble sauver la dimension morale de l'histoire. Cette interprétation est notamment défendue par M. J. Lacarra, Cuentística..., p. 90-92. Cependant, cette transparence morale du récit est peut-être trompeuse : on pourrait se demander si certains éléments de ce chapitre IV (les impasses de certaines actions juridiques, le fait que Dimna soit le seul narrateur de contes dans ce chapitre, la duplicité de certains de ses accusateurs, le manque de preuves pour étayer la condamnation finale...) ne sont pas autant d'indices qui inviteraient au soupçon. Loin de résoudre de façon simpliste la question de l'impunité du traître, le procès de Dimna multiplie les ambiguïtés et adopte une posture distanciée et critique vis-à-vis d'une vérité judiciaire en grande partie 
fabriquée. En ce sens, voir les remarques de Aboubakr Chraibi, «La réception de Kalîla et Dimna par la culture arabe ", in Aux origines du conte..., p. 77-88, notamment p. 83-84. En outre, si l'on rappelle que Dimna utilise les contes comme arguments de défense dans son propre procès, on voit comment la réflexion critique sur la notion de vérité judiciaire peut renvoyer aussi à une réflexion sur l'exemplarité et la vérité que les récits sont censés eux-mêmes produire.

17. Voir le texte et sa traduction en annexe.

18. 2 Samuel, 11, 2-17. Les motifs communs sont : le roi aperçoit une femme du haut d'un bâtiment élevé et désire la posséder alors qu'elle est mariée ; le mari (Urie, dans le récit biblique) est éloigné par le roi qui l'envoie à la guerre.

19. Contrairement à ce qui se passe dans le récit biblique, le mari n'est pas tué et l'adultère n'a finalement pas lieu.

20. Cette idée est très répandue dans la littérature politique orientale et occidentale du Moyen Âge. On lit dans l'Espéculo d'Alphonse X : «Todos los omnes deuen sseer tenidos de obedeçer las leyes, e mayormiente los rreys por estas rrazones : la primera porque sson por las leys onrrados e guardados ; la ssegunda porque los ayudan a conplir iustiçia e derecho, lo que ellos sson tenudos de ffazer ; la terçera porque ellos sson ffazedores dellas e es derecho que pues que las ellos ffazen que ellos las obedescan primeramiente. » (Titre I, loi 9, éd. G. Martínez Diez, Ávila : Fundación Sánchez Albornoz, 1985, p. 105).

21. Le conte 50 de El conde Lucanor de Don Juan Manuel reprend le même motif initial, mais le concept de « vergüenza " y est traité différemment. Le roi luxurieux, qui est Saladin dans cette version du conte, entreprend un voyage sapientiel pour répondre à l'énigme de la femme qui lui demande quelle est la meilleure chose au monde. À l'issue de son voyage, Saladin apprend que la réponse est précisément la « vergüenza » (« pudeur », plutôt que « honte » dans ce cas) et, par là même, il renonce à son désir coupable. Voir Daniel Devoto, Introducción al estudio de don Juan Manuel y en particular de «El conde Lucanor ", Madrid : Castalia, 1972, p. 462.

22. Il en va de même dans le Calila e Dimna où les contes sont systématiquement insérés par la formule « Dizen que » (« On raconte que »). Pour la valeur de « l'allégué » dans le régime véridictionnel médiéval, voir Alain Boureau, L'événement sans fin. Récit et christianisme au Moyen Âge, Paris : Les Belles Lettres, 1993, p. 33-37.

23. Cuentística medieval..., p. 56.

24. Voir le texte et sa traduction en annexe.

25. C'est ainsi qu'André Miquel, dans l'édition déjà citée, traduit le mot arabe pour lequel le traducteur castillan du XIIIe siècle n'avait pas trouvé d'équivalent. Voir sa note 45 , p. 329-330.

26. Ibid., note 46, p. 330. En outre, voir Calila e Dimna, note 76, p. 164.

27. On trouve ce conte sous forme de récit autonome dans le Panchatantra indien et c'est de ce corpus, connu également comme celui des « fables de Bidpaï », que La Fontaine s'est inspiré pour sa fable bien connue (Livre X, fable 2).

28. Les lignes qui suivent doivent beaucoup au commentaire de ce conte, pourtant lapidaire, que propose George Bossong dans « Sémantique et structures textuelles dans le livre de Calila e Dimna. Essai de théorie textuelle appliquée », Cahiers de linguistique hispanique médiévale, 4 (1979), p. 173-203 (voir p.193-194).

29. Sur ce point, voir l'intéressant travail théorique de Federico Bravo, « Poétique de l'exemple. Notes sur le livre de Calila e Dimna », Les langues néo-latines, 296 (1996), p. 19-36 (notamment p. 28-29, où l'auteur signale la différence fondamentale qu'il existe entre l'opération analogique de l'exemple et l'opération métaphorique). 
30. Je commente ici des expressions que je souligne dans le texte présenté en annexes. 31. La correspondance implicite entre Dimna et les deux canards est, par ailleurs, confirmée par le terme « consejo » à la fois employé pour désigner l'aide que les deux canards sont censés apporter à la tortue et pour résumer, dans les dernières lignes du texte, la portée du conte des pluviers telle que la conçoit Dimna, le narrateur.

32. Remarquons l'évolution de la modalité dans les expressions employées par les oiseaux à mesure que s'accroît leur nombre et se renforce leur cohésion. « Si así es commo tú dizes » répondent les amis du pluvier, comme s'ils étaient encore dubitatifs, et emploient ensuite le conditionnel « podríamos » pour envisager leur action. Par la suite, les autres oiseaux répondent, de façon nettement affirmative, « Así es commo vós dezides » et ils projettent leur action par un verbe conjugué à l'indicatif, " podemos ».

33. Je me réfère au raisonnement a fortiori : « quanto más el león que es tan atrevido et tan fuerte comme tú sabes ».

34. Cette interprétation est « implicite » parce que Dimna ne la pose pas comme telle, même si on pourrait la dire " quasi explicite ». On peut la dire « finale » parce qu'elle se surajoute à l'interprétation explicite et aussi parce qu'elle naît à la fin du récit, permettant en même temps le raccord du récit enchâssé au récit-cadre. « Quando lo sopo el mayordomo de la mar, entendió su flaqueza apos la fortaleza del falcón oriol »: l'ennemi de l'intendant est devenu le faucon plutôt que le pluvier.

35. De nombreux contes racontés par Calila, dans le même du chapitre, mettent en scène à l'intention de Dimna ce schéma de l'intrus finalement puni. C'est le cas, en particulier, de « La zorra aplsatada por dos cabrones monteses » ou de « La alcahueta y el amante » (p. 138-139).

\section{RÉSUMÉS}

À partir de l'étude de deux exempla, ce travail examine le fonctionnement de l'exemplarité dans le Calila e Dimna et le Sendebar (XIIIe siècle), en tenant compte des structures narratives de ces deux œuvres et de leur projet de transmettre un savoir. La thèse proposée est que le procédé d'enchâssement des récits, davantage que le recours à une "morale » explicite, détermine la portée éthique du texte.

A partir del estudio de dos exempla, este trabajo examina el funcionamiento de la ejemplaridad en el Calila e Dimna y el Sendebar (siglo XIII), teniendo en cuenta las estructuras narrativas de las dos obras y su proyecto de transmitir un saber. La tesis propuesta es que el procedimiento de la interpolación de relatos, más que el recurso a una moraleja explícita, determina el alcance ético del texto.

\section{INDEX}

Palabras claves : Calila e Dimna, Sendebar, Libro de los engaños

Mots-clés : exemplum, exemplarité

Index chronologique : XIIIe siècle 


\section{AUTEUR}

\section{OLIVIER BIAGGINI}

Université de Sorbonne Nouvelle - Paris 3 (UFR Études ibériques et latino-américaines Centre Censier - 75005 Paris), rattaché au LECEMO / CREM (FRE2374) et HAMCMM / SEMH (UMR5348). Domaine de recherches : littérature hispanique médiévale 